NBER WORKING PAPER SERIES

\title{
PAID SICK-LEAVE AND PHYSICAL MOBILITY: EVIDENCE FROM THE UNITED STATES DURING A PANDEMIC
}

\author{
Martin Andersen \\ Johanna Catherine Maclean \\ Michael F. Pesko \\ Kosali I. Simon \\ Working Paper 27138 \\ http://www.nber.org/papers/w27138 \\ NATIONAL BUREAU OF ECONOMIC RESEARCH \\ 1050 Massachusetts Avenue \\ Cambridge, MA 02138 \\ May 2020, Revised April 2021
}

Authors listed in alphabetical order. Special thanks to SafeGraph, a data company that aggregates anonymized location data from numerous applications in order to provide insights about physical places, for providing the data for this study. We thank Douglas Webber for helpful comments and Susie Van Doren for excellent editorial assistance. Dr. Pesko's effort on this project is supported by the National Cancer Institute of the National Institutes of Health under Award Number 1R01CA237888. All errors are our own. The views expressed herein are those of the authors and do not necessarily reflect the views of the National Bureau of Economic Research.

NBER working papers are circulated for discussion and comment purposes. They have not been peer-reviewed or been subject to the review by the NBER Board of Directors that accompanies official NBER publications.

(C) 2020 by Martin Andersen, Johanna Catherine Maclean, Michael F. Pesko, and Kosali I. Simon. All rights reserved. Short sections of text, not to exceed two paragraphs, may be quoted without explicit permission provided that full credit, including $(\mathcal{O}$ notice, is given to the source. 
Paid sick-leave and physical mobility: Evidence from the United States during a pandemic Martin Andersen, Johanna Catherine Maclean, Michael F. Pesko, and Kosali I. Simon NBER Working Paper No. 27138

May 2020, Revised April 2021

JEL No. H0,I1,J0,K0

\begin{tabular}{|c|c|}
\hline \multicolumn{2}{|c|}{ ABSTRACT } \\
\hline \multicolumn{2}{|c|}{$\begin{array}{l}\text { We study the effects of a massive temporary U.S. paid sick leave (PSL) mandate that became } \\
\text { effective April } 1 \mathrm{st}, 2020 \text { on self-quarantining, proxied by physical mobility behaviors gleaned } \\
\text { from cellular devices. Such behaviors are critical for containment of infectious diseases. The } \\
\text { national PSL policy was implemented in response to the COVID-19 global pandemic and } \\
\text { mandated two weeks of fully compensated paid leave. We study the impact of this policy using } \\
\text { difference-in-differences methods, leveraging pre-policy county-level differences in the share of } \\
\text { 'nonessential' workers likely eligible for paid sick leave benefits. We find robust evidence that } \\
\text { the policy increased the average number of hours at home and reduced the share of the } \\
\text { individuals likely at work. Comparing the county with the lowest to highest policy exposure, we } \\
\text { find that the average hours per day not at home, and at work decreased by } 8.9 \% \text { and } 6.9 \% \text { post- } \\
\text { policy. }\end{array}$} \\
\hline $\begin{array}{l}\text { Martin Andersen } \\
\text { Department of Economics } \\
\text { University of North Carolina at Greensboro } \\
\text { Bryan, Room } 448 \\
\text { Greensboro, NC } 27402 \\
\text { msander4@ uncg.edu }\end{array}$ & $\begin{array}{l}\text { Michael F. Pesko } \\
\text { Department of Economics } \\
\text { Andrew Young School of Policy Studies } \\
\text { Georgia State University } \\
\text { PO Box } 3992 \\
\text { Atlanta, GA 30302-3992 } \\
\text { mpesko@gsu.edu }\end{array}$ \\
\hline $\begin{array}{l}\text { Johanna Catherine Maclean } \\
\text { Department of Economics } \\
\text { Temple University } \\
\text { Ritter Annex } 869 \\
\text { Philadelphia, PA } 19122 \\
\text { and NBER } \\
\text { catherine.maclean@temple.edu }\end{array}$ & $\begin{array}{l}\text { Kosali I. Simon } \\
\text { O’Neill School of Public and Environmental Affairs } \\
\text { Indiana University } \\
1315 \text { East Tenth Street } \\
\text { Bloomington, IN 47405-1701 } \\
\text { and NBER } \\
\text { simonkos@indiana.edu }\end{array}$ \\
\hline
\end{tabular}




\section{Introduction}

In contemporary economically interconnected societies, infectious diseases can emerge and spread rapidly and lead to global sickness, death, economic decline, and numerous other social costs (see, for example, Adda (2016) and Agüero and Beleche (2017)). How best to curtail disease spread is an important question as the macroeconomic role of pandemics and other crises is increasingly recognized, and as pandemics become more common (World Health Organization 2018). Scientists develop vaccinations and medical treatments in response to a new disease, but these innovations take time and distribution plans must be established to widely deploy pharmacological responses to the population, a non-trivial task even in advanced economies. Infected and exposed individuals must self-quarantine to prevent further spread. Infectious disease can also increase family responsibilities, such as caring for dependents, and, thus, exacerbate existing labor market inequities between genders (e.g., Alon et al. (2020)).

Public health measures are, therefore, critical to contain disease spread in the early stages of a new infectious disease and remain crucial even after pharmacological responses are developed. ${ }^{1}$ If individuals face financial barriers to taking time off when sick or attending to family responsibilities, public health measures may not be adequately leveraged and disease spread may be exacerbated. A possible policy response to promote effective self-quarantining and meeting family responsibilities is providing workers with paid sick leave (PSL). Most developed countries mandate PSL and evidence suggests that individuals are more likely to selfquarantine when offered financial protection (Bodas and Peleg 2020).

\footnotetext{
${ }^{1}$ See for example https://www.cnn.com/2021/02/17/health/us-coronavirus-wednesday/index.html; https://www.jdsupra.com/legalnews/employers-should-think-twice-before-5276381/; and https://www.hrdive.com/news/dol-kansas-best-western-denied-paid-sick-leave-to-contracted-coronavirus/587947/ (all websites last accessed April $7^{\text {th }}, 2021$ ).
} 
To study the importance of PSL policy for promoting self-quarantining, we use data from the U.S., which is one of just three Organization for Economic Development (OECD) countries that does not have a national PSL policy, during the COVID-19 pandemic. The U.S. represents a unique case as it is an advanced economy that may face challenges to effectively employing a public health response to infectious diseases as working while sick is common, likely due to limited access to paid sick leave among workers. Indeed, without a federal mandate, provision of PSL benefits have largely been left to employers. Nearly $40 \%$ of employed U.S. adults report that they do not have any PSL through their employer (Asfaw, Rosa, and Pana-Cryan 2019).

As specific examples to demonstrate that limited PSL in the U.S. contributes to the spread of infectious disease, even in non-pandemic times, pre-COVID-19 survey data suggest that $90 \%$ of workers report working while sick (Accountemps 2019) and each week approximately three million Americans go to work while sick (Susser and Ziebarth 2016), including with infectious conditions (Smith 2008), possibly due to fear of income or job loss (NPR, Kaiser Family Foundation, and Harvard School of Public Health 2008). Foregoing wages is likely non-trivial for many Americans: In 2019 the cost of losing a day of wages was \$154.64 for the median worker (Gould 2020). Similarly, one in five Americans are caregivers and 61\% of caregivers work outside the home (The National Alliance for Caregiving and AARP 2020), suggesting that paid leave could allow many people to better balance work and family responsibilities, the latter of which may be exacerbated during pandemic periods due to widespread school and daycare closures, and general sickness.

In response to the COVID-19 pandemic, the U.S. federal government adopted a temporary national PSL policy designed to allow infected workers to stay home for two to twelve weeks when sick and/or when caring for dependents who became sick or children whose 
schools and daycares were shuttered. The initial two weeks were at full pay, and the additional ten weeks of paid leave carried a two-thirds replacement rate; both provisions had important exemptions. The policy, the Families First Coronavirus Response Act (FFCRA), was adopted on April $1^{\text {st }}, 2020$ and expired on December 31 $1^{\text {st }}$ 2020. The benefit can be claimed once, although days can be taken intermittently (Department of Labor 2020b). This policy reflects a massive investment of federal dollars -- over \$100B -- to PSL (Committee for a Responsible Federal Budget 2020). Understanding the response to a new PSL policy of this magnitude is important for economics literature on PSL, but also for pandemic response policies more broadly. Put differently, if these substantial federal resources do not translate into meaningful behavioral responses on the part of Americans and changes in disease outcomes, then policymakers may wish to reconsider other options to curtail disease spread.

We provide the first evidence on the impact of any U.S. PSL mandates on 'physical mobility,' an important behavioral outcome targeted by the policies, measured using proxies from GPS tracking of cellular devices. Specifically, we consider cellular device movements that plausibly capture time individuals spend at home, reflecting their ability to stay away from work when sick, to self-quarantine and to meet pandemic-associated family responsibilities.

We exploit a unique feature of the federal PSL policy: ‘Essential workers’ are exempt from FFCRA benefits and the share of such workers varies across U.S. counties pre-policy. ${ }^{2}$ While there are counties with very low (22.7\%) and very high (89.9\%) shares of nonessential establishments, in half of all counties, non-essential establishments account for 61.0 to $69.9 \%$ of the total. This variation allows us to estimate a difference-in-differences style (DD) model that

\footnotetext{
${ }^{2}$ As we discuss later in the manuscript, both fairly small and fairly large employers (below 50 and above 500 workers) are exempt from FFCRA. We exploit this source of variation in policy effects in our empirical models as well.
} 
leverages differential treatment 'doses'-based variation in the share of the county workforce that is employed in an 'essential' job. The federal government defines an essential worker who is employed in one of '.. .16 critical infrastructure sectors whose assets, systems, and networks, whether physical or virtual, are considered so vital to the United States that their incapacitation or destruction would have a debilitating effect on security, national economic security, national public health or safety, or any combination thereof' (U.S. Cybersecurity and Infrastructure Security Agency 2020). ${ }^{3}$ Example sectors include the chemical, communications, financial services, food and agriculture, healthcare and public, and transportation sectors. The intuition of this empirical strategy is that counties with higher shares of nonessential workers pre-FFCRA should be more exposed to the policy than counties with lower shares.

We find that FFCRA reduces the average hours away from home and the share of people likely at work (defined as away from their home for eight or more hours per day). Post-FFCRA, comparing the county with the lowest (22.7\%) share of nonessential workers in our data to the county with the highest share (89.9\%), the average number of hours not at home decreases (compared to pre-FFCRA values) by $8.9 \%$ and the share of individuals away from home for more than eight hours per day declines by 6.9\%. These results are confirmed through eventstudy comparisons -- the differences between highly exposed counties and counties with limited exposure are nonexistent prior to policy, and increase after the policy start date, and through placebo testing against 2019 data and numerous other robustness checks.

The paper is organized as follows. Section 2 outlines the related literature on PSL mandates. FFCRA is discussed in Section 3. Data, variables, and methods are described in Section 4. Results are listed in Section 5 and Section 6 concludes.

\footnotetext{
${ }^{3}$ As we discuss in Section 3, there is no official federal definition of an essential worker.
} 


\section{Related literature}

\subsection{PSL mandate effects}

There is a growing economic literature on PSL mandates. Much of the literature has focused on non-U.S. settings as the U.S. has only recently adopted PSL mandates, and only at the city and state level. We focus on U.S. PSL mandates as they are most relevant to our work. ${ }^{4}$

While there have been attempts to adopt a federal PSL policy within the U.S., beginning with the 'Healthy Families Act' advocated by Senator Ted Kennedy in 2005 and re-introduced in 2019 after several failed attempts to pass the Act, lack of bipartisan support has prevented legislative movement at the federal level in this sphere. U.S. cities and states have attempted to address the lack of federal PSL and adopted their own mandates, beginning with the city of San Francisco, California in 2007. By April 2021, 34 cities and states had adopted a PSL mandate (A Better Balance 2021). While there is heterogeneity in accrual periods, size exclusions, and eligible use of the leave across these local mandates, all mandates to date are employer mandates and on average require eligible employers to offer seven days of fully compensated paid sick leave (A Better Balance 2021). Due to limited administrative databases on PSL within the U.S., the available research has largely leveraged survey data to study mandate effects.

U.S. city and state PSL mandates in general increase PSL coverage among workers (Maclean, Pichler, and Ziebarth 2020; Callison and Pesko 2020). As described by Stearns and White (2018), the overall effect of these PSL mandates on leave-taking for illness-related reasons is ex ante ambiguous. ${ }^{5}$ However, most studies to date suggest that following a city or state PSL

\footnotetext{
${ }^{4}$ We note that there are other forms of paid leave such as family and maternal leave that localities have mandated. ${ }^{5}$ Stearns and White carefully outline that for those workers who gain access, there is the direct effect that leave will increase and the workers will stay home when sick. However, for all workers, there will be less illness within the workplace which could reduce overall need for illness-related leave. These impacts on leave-taking operate in opposite directions, leaving the net effect unclear.
} 
mandate, workers take additional paid leave (Callison and Pesko 2020; Maclean, Pichler, and

Ziebarth 2020; Schneider 2020; Colla et al. 2014; Ahn and Yelowitz 2016). We note that

Stearns and White (2018), using variation from Connecticut and Washington, DC (early adopting

localities in the U.S.), show that overall leave-taking declines post-mandate. ${ }^{6}$

PSL can allow workers to take time away from work to recover from their own illness, to care for dependents, or for other reasons. Several studies are able to evaluate heterogeneity in the type of absences taken post-PSL mandate. Stearns and White (2018) find that PSL mandates adopted in Connecticut and Washington, DC decrease illness-related work absences by 18\%, but do change work absences for non-illness reasons (e.g., childcare during school or daycare closures). In contrast, Callison and Pesko (2020) do not find evidence that city and state PSL mandates increase work absences nationally for one’s own illness, but the authors document increases in leave-taking for a broader group of absences, including child-care problems or personal/family obligations, and these effects are larger for households with children.

Additionally, city and state PSL mandates may improve worker productivity - potentially by allowing workers to remain home while sick and recover more quickly, or to reduce work-life balance strain attributable to struggles to meet family responsibilities. For example, Callison and Pesko (2020) find evidence that city and state PSL mandates reduce presenteeism (i.e., working

\footnotetext{
${ }^{6}$ Several studies examine European reforms that change the coverage generosity of a pre-existing PSL national program (e.g., lower the wage replacement rate for paid sick days) rather than study the adoption of a specific mandate that provides fully compensated PSL benefits to workers for the first time. These reforms have not yet been adopted in the U.S. (where the mandating of PSL is more recent) and our evidence is based on European experiences. The available research suggests that reductions in PSL coverage generosity reduce days away from work (Puhani and Sonderhof 2010; Ziebarth and Karlsson 2010; Ziebarth and Karlsson 2014; Böckerman, Kanninen, and Suoniemi 2018; De Paola, Scoppa, and Pupo 2014; Henrekson and Persson 2004; Scognamiglio 2020). In addition, a few studies using European data examine the effect of PSL mandate generosity on measures of healthcare utilization and health outcomes. For example, using data from Germany Puhani and Sonderhof (2010) find that a temporary increase in PSL generosity reduced hospitalizations and hospital visits. However, there is limited evidence that mandated time away from work improves measures of self-assessed health (Puhani and Sonderhof 2010; Ziebarth and Karlsson 2014).
} 
while sick), and a study shows that the Washington state PSL mandate reduces presenteeism among retail and food service workers (Schneider 2020).

Of particular relevance to our study, two studies that exploit variation generated by U.S. city and state PSL mandates shows that these policies reduce infectious disease spread in nonpandemic times. Pichler and Ziebarth (2017) use high-frequency Google influenza data in the U.S. to show that population-level influenza-like disease rates (as measured by searches related to the illness or its symptoms) decrease after workers gain access to PSL following a city or state mandate adoption, suggesting PSL mandates have positive spillover effects by preventing disease spread. In a follow-up study using administrative data on physician-certified influenza, Pichler, Wen, and Ziebarth (2020b) confirm this finding.

No studies to date have considered PSL policy adopted during a pandemic on measured aggregate physical mobility measures. We address both of these gaps in the existing PSL literature in our study. First, FFCRA was adopted during the COVID-19 pandemic and so we are able to use quasi-experimental methods to study the impact of a PSL mandate on physical mobility measures. Second, we are able to measure aggregate physical mobility due to our use of aggregate-level cellular-tracking data. The aggregate impact of PSL on mobility is likely the most relevant outcome during a pandemic. Put differently, if the worker stays away from home due to financial protection afforded by PSL but does not reduce mobility in total, then the effectiveness of PSL mandates as policy tool for reducing community spread of an infectious disease is likely reduced. Our study is able to speak directly to these issues.

\subsection{COVID-19}

The COVID-19 pandemic is the largest pandemic in modern history and thus offers a unique opportunity to study the importance of PSL policy for promoting basic public health 
measures such as staying home while sick/exposed. As of April $7^{\text {th }}, 2021$ there were over 132 million confirmed global COVID-19 cases and more than 2.8 million deaths (World Health Organization 2020). The U.S. accounts for $23 \%$ of confirmed cases and $19 \%$ of deaths globally. COVID-19 is a viral disease caused by infection with the virus SARS-CoV-2. Infected individuals are contagious for a period of up to 14 days and before displaying symptoms (e.g., dry cough and fever), thus increasing the importance of strategies to enable sick workers to remain at home and for workers to take time away from work to care for exposed or sick dependents. The U.S. response to curtailing COVID-19 through public health measures has been criticized (Yong 2020; Altman 2020). While there are likely myriad reasons, lack of PSL potentially played a role as has been established in previous pandemics. For example, Kumar et al. (2012) estimate that five million Americans contracted influenza during the 2009 H1NI outbreak due to a lack of PSL.

\section{FFCRA}

FFCRA compels certain private employers with 50 to 500 workers and some public employers to offer temporary paid leave to workers (Federal Register 2020). ${ }^{7}$ FFCRA also applies to the gig economy (e.g., Uber). Qualifying reasons for PSL include: (i) worker is subject to a federal, state, or local quarantine or isolation order; (ii) a healthcare professional has recommended that the worker self-quarantine; (iii) the worker is experiencing COVID-19 symptoms or similar symptoms and is currently seeking a diagnosis from a healthcare professional; (iv) the worker is caring for an individual(s) subject to (i) or (ii); and (v) the worker is caring for a child whose school or daycare is closed, or whose childcare provider is not

\footnotetext{
${ }^{7}$ To date, we are not aware of data on the number of individuals who have taken up FFCRA benefits.
} 
available for reasons related to COVID-19. ${ }^{8}$ Early estimates suggest that FFCRA will cover $17 \%$ to $47 \%$ of U.S. workers (Glynn 2020).

FFCRA provides eligible workers with a qualifying own or family illness and, as we discuss later in the manuscript, additional pandemic-related reasons with two weeks (up to a maximum of 80 hours) of PSL at the worker's regular rate of pay or the applicable minimum wage (whichever is higher), up to a maximum of \$511 per day, once, during 2020. Employers are not permitted to reduce other benefits following FFCRA adoption and FFCRA benefits can be used in conjunction with previously provided paid leave (e.g., city and state mandated PSL). Workers who are caring for children whose schools or daycares have closed due to COVID-19 or who are tending to dependents with COVID-19 are also eligible for two weeks (up to a maximum of 80 hours) of PSL at the full cost of the worker's regular rate of pay, or the applicable minimum wage, up to \$200 per day. Employers initially pay the benefits, but later receive federal reimbursable tax credits (Internal Revenue Service 2020). There is no accrual rate or waiting period for benefits; such features are common among U.S. city and state mandates to date (e.g., most city and state mandates impose a waiting period of $60+$ days).

Additional benefits are available to some workers (who have worked for the employer for more than 30 days) under The Emergency Family and Medical Leave Expansion Act, which predates COVID-19 and extends Title I of the Family and Medical Leave Act that provides 12 weeks unpaid leave to qualifying workers. FFCRA now gives employers reimbursements (up to two-thirds of the regular wages) for ten weeks of such leave, making FMLA into a paid sick leave policy (Department of Labor 2020a). Employers must post notices in the workplace so that workers know about the benefit.

\footnotetext{
${ }^{8}$ Research suggests that childcare became more scarce over our study period (Ali, Herbst, and Makridis 2021).
} 
Of particular relevance to our study, 'essential workers' who work in one of 16 'critical infrastructure sectors’ (U.S. Cybersecurity and Infrastructure Security Agency 2020) ${ }^{9}$ and are employed by employers with 50 to 500 workers are exempt from receiving FFCRA benefits (Federal Register 2020). The Department of Labor (DOL) has not explicitly defined an 'essential worker,' ${ }^{10}$ although they must work in one of the 16 above-noted sectors. Within FFCRA legislation, the DOL states that essential workers are individuals who '(i) interact with and aid individuals with physical or mental health issues, including those who are or may be suffering from COVID-19; (ii) ensure the welfare and safety of our communities and of our Nation; (iii) have specialized training relevant to emergency response; and (iv) provide essential services relevant to the American people's health and wellbeing' (Federal Register 2020). The DOL delegates the exact definition of essential workers to states: 'Therefore, the definition allows for the highest official of a state or territory to identify other categories of emergency responders, as necessary.' As we discuss in Section 4.3, we use a definition of essential workers developed by Blau, Koebe, and Meyerhofer (2020), and leverage differences across counties in the share of the workforce that is likely classified as a nonessential worker.

As discussed above, a county’s exposure to FFCRA depends on the share of workers who are eligible for FFCRA benefits. We approximate this value using the share of workers in nonessential industries. However, since employment data is frequently suppressed in the Quarterly Census of Employment and Wages (QCEW) at the county-by-industry level that we need, we employ an iterative proportional fitting (IPV) procedure (Bacharach 1965) to estimate

\footnotetext{
${ }^{9}$ The 16 sectors include: chemical; commercial facilities; communications; critical manufacturing; dams; defense industrial base; emergency services; energy; financial services; food and agriculture; government facilities; healthcare and public health; information technology; nuclear reactors, materials, and waste; transportation systems; and water and wastewater systems.

10 The DOL uses the term 'essential responder.' We use the common colloquial term 'essential worker.'
} 
employment at the county-by-industry level (see the Data Appendix for full details on how we construct this measure). We report results based on specifications that use (i) nonessential worker establishments (directly observed in the QCEW) and (ii) nonessential workers that we derive from our IPV estimates. We view both measures as proxies for the number of nonessential workers in a county. Our findings are not sensitive to the proxy we employ. In complementary analyses, we make use of our IPV estimates that incorporate employer size to more accurately identify the share of workers in non-essential employers with 50 to 500 workers. We chose not to use this measure as our primary proxy as we must impute both industry and employer size. However, we have re-estimated all analyses reported in this paper using the 'doubly imputed’ IPV measure and results (available on request) are very similar.

\section{Data, outcome variables, and methods}

\subsection{SafeGraph Inc.}

We use aggregated, high frequency (daily) geolocation data from SafeGraph Inc. (a company that aggregates anonymized location data from numerous cellular applications) covering the period March $13^{\text {th }}, 2020$ through April $30^{\text {th }}, 2020 .{ }^{11}$ We select March $13^{\text {th }}, 2020$ in particular as the start date of our study window as this is the date on which then-President Trump declared a national emergency (Federal Emergency Management Agency 2020) and potentially reflects a meaningful change in the understanding of the COVID-19 pandemic among Americans. We exclude earlier days in March as the economy-wide reductions in mobility had not occurred then (see Gupta et al. (2020) for a review of the literature on the effect of closure policies on different economic outcomes, including mobility). In a paper that investigates changes in mobility, Cronin and Evans (2020) estimate structural break models borrowed from

\footnotetext{
${ }^{11}$ Please see www.safegraph.com (last accessed April $7^{\text {th }}$, 2021).
} 
macroeconomics and findings clearly establish that mobility among Americans changed dramatically between March $8^{\text {th }}$ and March $14^{\text {th }}$. As a specific example of the shift in behavior among Americans at this time, the authors show that over a three-day period (March $10^{\text {th }}$ to $12^{\text {th }}$ ) 45 states experienced a structural break in the share of people at home all day. See Appendix Figure A2 in the Cronin and Evans (2020) study. However, our results (available on request) are robust to using any start date within the Cronin and Evans (2020) window.

Our methods, difference-in-difference style models, rely on common trends in our outcomes. COVID-19 was a massive shock to the U.S. and different counties likely had differential responses in terms of mobility due to labor markets, social norms, understanding of/belief in public health experts, and so forth (Allcott et al. 2020). Therefore, we focus on trends in the 'early COVID-19 environment' as that period is most salient to our study and, in particular, to the validity of our research design. We close the study period on April $30^{\text {th }}, 2020$ as several states began the process of re-opening their economy in early May 2020 (The Council of State Governments 2020). As we show in robustness checking (Section 5.5), our results are insensitive to using longer and shorter study periods.

SafeGraph data cover over 20-million cellular devices and are freely available to researchers. These data allow us to accurately locate individual cellular devices and track the share of devices that leave the home area in near real-time and are, therefore, ideal for our study. SafeGraph identifies locations for a device using a GeoHash-7 encoding algorithm that covers the globe with a grid that is approximately 500 feet per side. Devices are included in the sample if SafeGraph can identify a home location for the device, which requires a device to be on and consistently present at a location during nighttime hours for a six-week period. Because SafeGraph data are based on users of cellular applications who have opted into location sharing, 
the number of devices in the sample changes over time. ${ }^{12}$ Given our short study period, the above-noted six-week requirement, and the kinds of applications that provide location data, we do not expect that the sample of cellular devices to be a function of FFCRA implementation.

SafeGraph excludes Census block group information with fewer than five active devices on a given day. We aggregate the number of active devices in each county, the average time devices remained away from home, ${ }^{13}$ and the fraction of devices that were away for eight or more hours, from census block groups to the relevant county. To isolate FFCRA effects, in our main analysis we use counties that were not covered by a PSL mandate prior to FFCRA (A Better Balance 2021). This exclusion allows us to focus on a sample that does not have any form of mandated PSL and are most likely to newly benefit, though we show in robustness checking that our findings are robust to including all counties, which supports the hypothesis that both types of counties benefit from the policy. ${ }^{14}$ Appendix Table 1 lists localities with a pre-FFCRA PSL mandate. The study sample includes 2,757 counties and county equivalents out of a total of 3,143 in the country; we do not differentiate between counties and equivalents. ${ }^{15}$ We observe

\footnotetext{
${ }^{12}$ Examples of application types include weather and mobile retail applications. As such devices are likely actively transmitting their locations throughout the day if a device is moving.

${ }^{13}$ SafeGraph reports median hours. Given this data reporting structure, we calculate mean time away from the home using the midpoint of binned categories reported by SafeGraph.

${ }^{14}$ Employees in counties with a pre-FFCRA city or state PSL mandate in place can benefit from the federal policy leave as this newly obtained leave can be used in addition to any leave mandated by earlier policies. Further, in unreported analyses available on request, we allow for an interaction between our exposure measure and a preFFCRA PSL policy, the interaction coefficient estimate is imprecise and small in magnitude.

${ }^{15}$ One may view cities and states with a pre-FFCRA PSL mandate as a potential comparison group that could be leveraged in a reverse DD specification (Gruber 1994). However, the pre-FFCRA policies are quite different in terms of the workers covered, conditions for which the benefits can be used, accrual rate, waiting period, and the fact that city and state PSL mandates are permanent pieces of legislation while FFCRA is a temporary policy which expired at the end of 2020. As a specific example, non-essential workers and workers at employers with 500 or more workers are included in city and state PSL mandates, on the other hand FFCRA covers those employed in the gig economy while city and state mandates generally do not. Further, there are accrual rates and waiting periods for most city and state PSL mandates while there are no such barriers for FFCRA benefits. FFCRA allows benefits, for some workers, to be extended up to ten weeks of paid leave through the Emergency Family and Medical Leave Expansion Act, which is not possible with city and state mandates. Finally, the Department of Labor specifically states that FFCRA benefits can be used in addition to previously available benefits, so both localities with and without a pre-existing PSL policy treated by FFCRA. In sum, these are different benefits. For these reasons, we are not confident in estimating such a reverse DD specification. However, in unreported analyses available on request,
} 
each county in each of the 48 days in our study period, thus the sample is balanced. We exclude weekends as most work and school/daycare activities occur within the standard work week (although as we show in robustness checking, results are not sensitive to including such days).

\subsection{Outcomes}

We consider two physical mobility outcomes based on the movement of cellular devices (not individuals) that proxy for the ability to remain at home while sick and/or caring for dependents. Ideally, we would measure actual time at home, but high-frequency data are not available for the period required for our empirical strategy. ${ }^{16}$

We measure the average number of hours per day that the cellular device spends not at home in each county. We also examine the share of devices that are not at home more than eight hours per day. We select eight hours as this duration plausibly captures a work or daycare/school day; both of these behaviors could be impacted by FFCRA as the policy provides benefits for parents/guardians who are caring for children not at daycare/school or who are sick. ${ }^{17}$ Thus, while we use terms such as 'individual' when discussing our results, we note that we are in fact tracking cellular devices which are, presumably, carried by an individual.

\subsection{Methods}

To estimate FFCRA effects, we estimate a modified DD-style model (Alpert, Powell, and Pacula 2018; Powell, Alpert, and Pacula 2019; Park and Powell 2021; Powell and Pacula 2021; Beheshti 2019; Finkelstein 2007; Argys et al. 2020; Courtemanche et al. 2017). This model

\footnotetext{
we estimate this reverse DD specification. Our findings are inconclusive, which we attribute to the above-noted differences across FFCRA, and city and state PSL mandates.

${ }^{16}$ For example, if an individual does not take their cellular device with them when they leave their home for work, then we will not capture this working behavior and instead we would, erroneously code this individual as at home. We cannot envision any reason why the propensity to carry a cellular device vs. leaving the device at home, should be correlated with FFCRA implementation (and its heterogenous exposure across counties attributable to the share of nonessential workers in the local labor market) over our relatively short study period.

${ }^{17}$ Individuals must be 13 years or older to be included in the SafeGraph sample. Thus, elementary and middle school students are not included in the sample, but high school and college students may be included.
} 
leverages variation in treatment intensity that is attributable to differences in pre-treatment characteristics across counties. The intuition is that we should observe larger FFCRA effects in counties which had higher shares of nonessential workers pre-FFCRA as these are the workers who are potentially eligible for policy benefits. Put differently, there is likely to be more policy 'bite' in such counties as a greater share of the workforce is eligible for FFCRA.

In particular, we interact an indicator for the post-FFCRA period (April 1 ${ }^{\text {st }}, 2020$ through April $30^{\text {th }}, 2020$ ) with the share of workers in a county employed in a 'nonessential worker' job in the first quarter of 2019 using data from the Bureau of Labor Statistics' QCEW. The QCEW captures the near universe of establishments in the U.S. An establishment is: 'A single physical location where business is conducted or where services or industrial operations are performed.' A limitation of this variable is that we use establishments rather than workers themselves to proxy nonessential workers. ${ }^{18}$ Thus, as described in Section 3.2 and the Data Appendix, we construct a statistical estimate of employment by industry within counties. We also construct estimates of the number of establishments and employees within county-industry-employer size cells. Both measures - which we view as proxies for the share of the county impacted by FFCRA - have benefits and costs, therefore, we report results using both.

Essential workers are not eligible for FFCRA benefits and counties with greater shares of nonessential workers should be more exposed to the policy and, correspondingly, if FFCRA impacts our proxies, should experience larger changes in outcomes post-policy. The DOL has not established a definition of essential workers, but instead provides a high-level description and leaves definition to states (see Section 3). There is heterogeneity across states (but not across counties within a state) in the effective definition. We follow the definition outlined by Blau,

\footnotetext{
${ }^{18}$ While the QCEW contains some information on the number of workers, there is substantial suppression at the county-industry level due to privacy concerns. Hence, we cannot use this information.
} 
Koebe, and Meyerhofer (2020), although our results are robust to using an alternative definition. ${ }^{19}$ This definition is reasonable as there is no federal standard.

The regression model for our modified DD-style model is outlined in Equation (1):

$$
Y_{c, s, t}=\pi_{0}+\pi_{1} F F C R A_{t} * \text { nonessential } l_{c, s}+P_{s, t} \pi_{2}+D_{c, s, t} \pi_{3}+\delta_{c}+\theta_{t}+\eta_{c, s, t}
$$

Where $Y_{c, s, t}$ is a physical mobility (e.g., remaining home while sick, carrying for dependents) outcome in county $c$ in state $s$ in time $t$. FFCRA $t$ is the post-FFCRA indicator and nonessential $_{c, S}$ is the fraction of nonessential workers in county $c$ in state $s$ the first quarter of 2019 (using one of our two proxies: nonessential worker establishments or a probabilistic measure of nonessential workers). $P_{s, t}$ is a vector of state-level COVID-19-related policies (public school closures, stay at home orders, nonessential business closures, and prohibition on in-restaurant dining (Raifman 2020)) and $D_{c, s, t}$ is a vector of county-level weather variables, ${ }^{20}$ the latter of which likely impact our physical mobility measures independent of an pandemic. $\delta_{c}$ and $\theta_{t}$ are county and day fixed-effects, respectively. Nonessential $l_{c, s}$ is time-invariant and, thus, we do not include the main effect as this variable is perfectly collinear with county fixedeffects. Indeed, our county fixed-effects will control for all time-invariant factors over our study period (e.g., labor market structure). We do not control for confirmed cases or deaths attributable to COVID-19 in our main specifications as we are concerned that these variables would be endogenous if changes in mobility affect COVID-19 incidence. However, we show in

\footnotetext{
${ }^{19}$ We include the following NAICS codes: $111,112,114,115,22,23,311,3121,3221,32222,32223,32229$, 3251, 3253, 3254, 3256, 3259, 33311, 3341, 3342, 3343, 3345, 3344, 3346, 3352, 3391, 4233, 4234, 4237, 4241, 4242, 4244, 4245, 4246, 4247, 4248, 4249, 4441, 44511, 44512, 4452, 4453, 4523, 454110, 44611, 447, 481, 482, 484, 4851, 4852, 4853, 4854, 4855, 4859, 491, 492, 493, 51111, 515, 517, 5182, 51913, 521, 52211, 52219, 52212, 52213, 5222, 5223, 523, 5241, 5412, 5415, 5416, 5417, 54194, 5525, 5617, 56173, 562, 616, 6211, 6212, 6213, 6214, 6215, 6216, 6219, 6221, 6222, 6223, 6231, 6232, 6233, 6239, 6241, 6242, 6244, 7211, 722, 8111, 8112, 8113, 8122, 8123, 92111, 92112, 92113, 92114, 92115, 92119, 922, 923, 924, 925, 926, 927, and 928. We exclude the following NAICS codes: 311811, 42491, 44413, 517311, 56173, 62131, 62132, 7224, and 811192.

${ }^{20}$ Weather variables accessed at https://github.com/jbayham/gridMETr (last accessed April $7^{\text {th }}, 2020$ ).
} 
Section 5.3 our results are not sensitive to their inclusion. In addition, given the high-frequency and geographic granularity of our data (recall we measure outcomes at the daily level in the county) many variables that we would like to include in the regression model (e.g., daily countylevel unemployment rates) are not available to us, though our $P_{s, t}$ vector includes a great number of potential sources of within county, time-varying omitted variable bias. ${ }^{21}$ We estimate least squares regressions. The data are weighted by the county population. We cluster standard errors at the county level (Bertrand, Duflo, and Mullainathan 2004).

Given that we leverage county-level variation in nonessential workers, discussing the type of worker affected by FFCRA is worthwhile. Blau, Koebe, and Meyerhofer (2020) carefully examine demographics of essential and nonessential workers. Nonessential workers (vs. essential workers) are slightly more likely to be male, have similar wages, are more likely to be racial or ethnicity minority, and have lower education. Further, the authors note that there is a similar distribution of nonessential and essential workers across broad occupational groupings.

We also explore county-level correlates of the share of nonessential workers. To this end, we regress this share on the following county-level variables: average age, sex-distribution, race and ethnicity, insurance coverage, unemployment rate, poverty level, and population. Demographic variables are drawn from the 2015 to 2019 American Community Survey (ACS) (Ruggles et al. 2021). 35\% of the U.S. population resides in counties that are suppressed in the ACS; these are more rural counties. We assign these counties the average value in all suppressed counties over this period. We report results for both nonessential worker proxies (Table 1).

\footnotetext{
${ }^{21}$ We note that one could view our treatment variable as shift-share variable. That is, FFCRA is the shift and the shares are the counties that vary in their FFCRA exposure based on pre-policy nonessential workers and employer size.
} 
We observe that the share of nonessential establishments is correlated with age, Black, and average income, while the share of workers in nonessential employers is also correlated with the share of the population that is another non-White race, or of Hispanic ethnicity and negatively correlated with the unemployment rate. Including weather controls does not appreciably alter the correlations with county-level demographics.

\section{Results}

\subsection{Summary statistics and trends}

Table 2 provides summary statistics in the pre-FFCRA period. The average number of hours away from home is $4.5 .^{22} 28.6 \%$ of individuals in a county are away from home more than eight hours per day and 65.1\% (55.4\%) of establishments (workers) are nonessential. While there is no other policy that occurred nationwide on April $1^{\text {st }}, 2020$ that might confound our effects, controlling for state social distancing policies and county weather variables allows us to arguably better isolate FFCRA effects.

Figures $1 \mathrm{~A}$ and $1 \mathrm{~B}$ report variation in our nonessential worker proxies. The share of nonessential workers varies across U.S. counties (Figure 1A). We note that several states have low shares of nonessential workers while others have higher shares. Indeed, the two states that arguably appear to be the most discordant actually border each other: California and Oregon. Apart from these states, the distribution of nonessential worker establishment does not show a strong geographic trend, with most states including counties with both very high and very low shares of such establishments. Indeed, adjacent counties within the same state often have very different levels of nonessential worker establishments. $34.0 \%$ of the establishments in Fresno

\footnotetext{
${ }^{22}$ Time away from home is reported in buckets of 20 minutes or less, 21 to 45 minutes, 46 minutes to one hour, one to two hours, two to three hours, three to four hours, four to five hours, five to six hours, six to seven hours, seven to eight hours, eight to nine hours, nine to ten hours, ten to 11 hours, 11 to 12 hours, 12 to 14 hours, 14 to 16 hours, 16 to 18 hours, 18 to 20 hours, 20 to 22 hours, and 22 hours or more.
} 
County California, for example, are nonessential, while in neighboring Mono County, California we classify $85.1 \%$ of establishments as nonessential. Figure $1 \mathrm{~B}$ depicts a histogram of the share of nonessential workers; the distribution is roughly bell-shaped but does display a modest right skew. The range is $23.1 \%$ to $92.1 \%$ nonessential workers.

Trends in our outcome variables over the study period are reported in Figures 2A and 2B. We report the difference between 2020 and 2019 for each variable (we use comparable dates in each year ${ }^{23}$ ) and aggregate to the weekly level to smooth out noise inherent in the highfrequency data we use. We observe some evidence of a change in trend in our outcomes on April $1^{\text {st }}, 2020$. We have also evaluated trends for the counties at the $1^{\text {st }}$ and $4^{\text {th }}$ quartiles of the exposure distributions, the changes on April $1^{\text {st }}, 2020$ are more pronounced at the $4^{\text {th }}$ quartile.

A critical component of our analysis is determining the pre- and post-policy periods. Put differently, is April $1^{\text {st }}, 2020$ a meaningful break? This is the date on which FFCRA became effective, which supports our definition of the pre- and post-periods. Further, as we show in robustness checking, we cannot replicate our findings using placebo effective dates. Finally, we have conducted tests for structural breaks. In particular, we estimate a linear-in-time structural break model from the macroeconomics literature, and following Cronin and Evans (2020), for each date from March $20^{\text {th }}$ to April $23^{\text {rd, }}$ 2020. From this analysis, we compute the F-statistic on an indicator for a level-shift on each date and a shift in the slope of a linear time trend on that date. These F-statistics, which are plotted in Appendix Figures 1A and 1B, demonstrate that there was a large break in the time trend on April 1 ${ }^{\text {st }}, 2020$ which supports our empirical design.

\subsection{Effect of FFCRA on physical mobility}

\footnotetext{
${ }^{23}$ We construct comparable dates using epidemiological weeks - the number of weeks that have elapsed since the first Sunday of a week containing at least four days of a given year-and the day of the week. For example, April $1^{\text {st }}, 2020$ is the Wednesday of the $13^{\text {th }}$ epidemiological week; the corresponding date in 2019 is April $3^{\text {rd }}$.
} 
Results based on our baseline specification are reported in Tables 3A (using nonessential worker establishments) and 3B (using nonessential workers). We observe that for a hypothetical county that moved from having $0 \%$ nonessential workers to $100 \%$ nonessential workers, the average hours not at home and the share of devices not at home for more than eight hours per day in the post-FFCRA period decreased. We do not observe such a county in our data and thus transform the coefficient estimates to reflect a pattern that we do observe in real-world U.S. counties (see Figure 1A). In particular, we scale our estimates by 0.671 in our nonessential worker establishment specifications, this scaling factor reflects the difference in exposure in the county with the lowest (22.7\%) and the county with the highest (89.9\%) share of nonessential establishments in 2019 quarter one. For our probabilistic measure of nonessential workers, we use one as the scaling factor as the minimum and maximum of the employment share variable are zero and one.

Using these transformations, we find that FFCRA leads to a 0.38 hour or 22.9 minute decrease in average time away from home and a 1.8 ppt decrease in the share of devices away from home eight more hours per day. In relative terms (calculated by comparing the coefficient estimates to the pre-FFCRA sample means), our findings imply $8.9 \%$ and $6.9 \%$ changes in the outcomes. Results using the share of non-essential employees in the county are broadly similar, with a 0.273 hour decrease in time not at home (16.4 minutes) between counties with $0 \%$ vs $100 \%$ nonessential workers. The reduction in devices away from home for eight hours or more is slightly smaller using the employment share, as opposed to establishment share (1.1. vs 1.8 percentage points). Relative to the average levels of these variables in the pre-period, we find changes of $-6.3 \%$ and $-4.2 \%$, respectively. 
We also report two alternative transformations in all regression tables that display coefficient estimates generated in Equation (1): (i) a one standard deviation (SD) increase in the share of nonessential establishments (6.0\%) or workers $(7.6 \%)$ and (ii) moving from the $10^{\text {th }}$ (61.3\% and $48.3 \%$ for nonessential worker establishments and workers) to $90^{\text {th }}$ ( $75.5 \%$ and $67.3 \%$ for nonessential worker establishments and workers) percentile of the empirical distribution (see Figure 1B). We report these alternative transformations for transparency given that there is no standard scaling approach of which we are aware. These transformations necessarily imply smaller changes post-FFCRA as we are comparing more similar counties.

During our study period, states were active in implementing social distancing policies. Similar to other studies in the literature (Gupta et al. 2020), we observe that state-level social distancing policies generally decrease time away from home, with some variation in terms of both the magnitude and statistical significance across policies. ${ }^{24}$

In Table 3C, we report results using IPV measures that incorporate employer size, namely nonessential employers with 50 to 500 workers (Panel A) and nonessential workers employed at employers with 50 to 500 workers (Panel B). As noted earlier, this measure - while more accurate in terms of isolating employer size (recall that FFCRA impacts employers with 50 to 500 workers) - requires that we impute both industry and employer size. Thus, we are concerned that 'doubly' imputing may inflate measurement error. However, the results reported in Table 3C are very similar to those reported earlier (i.e., Tables 3A and 3B). After scaling, ${ }^{25}$ post-FFCRA (comparing the most to the least exposed county in the U.S.) the average hours at

\footnotetext{
${ }^{24}$ We observe no clear pattern of results from interactions between FFCRA and social distancing policies (not reported but available on request), suggesting no conclusive evidence on whether FFCRA enhanced the effectiveness of these policies over our study period.

${ }^{25}$ The scaling factor (comparing the counties with the lowest and highest shares of exposure observed in the data) for Panel A in Table 3B is 0.039 while the comparable scaling factor in Panel B is 0.520.
} 
work decline by 0.282 hours while the share of cellular devices not at home eight or more hours per day declines by 1.3 ppts using the nonessential employer exposure measure. The comparable (scaled) post-FFCRA declines are 0.166 hours ${ }^{26}$ and 1.0 ppts when using the IPV variable that measures employees.

\subsection{Internal validity}

We next probe the robustness of our design to various threats to identification. First, we explore the ability of our data to satisfy parallel trends. Second, we investigate the importance of unobserved confounders. Finally, we conduct falsification exercises to ensure that we are not erroneously capturing the effect of some other policy or factor that was also adopted nationwide on April 1 $1^{\text {st }}$, 2020; of note, we are not aware of any such policy or factor.

Parallel trends: We estimate a modified event-study model to explore the ability of our data to satisfy the parallel trends assumption that is necessary for DD-style models to estimate causal effects. In particular, we interact the county pre-FFCRA share of nonessential establishments with indicators for the weeks beginning March $18^{\text {th }}$, March $25^{\text {th }}$, April $1^{\text {st }}$, April $8^{\text {th }}$, April $15^{\text {th }}$, April $22^{\text {nd }}$, and April $29^{\text {th }}$. We select the week of March $18^{\text {th }}$ as the omitted category as it is the earliest period in our sample (Lovenheim 2009). Otherwise, the event-study equation is identical to Equation (1). Results are reported graphically in Figures 3A and 3B; note these figures depict the coefficient estimates and are not scaled in any way. Broadly, these figures suggest that counties with higher and lower shares of nonessential establishments followed similar trends preFFCRA. However, beginning on April $1^{\text {st }}$, 2020, counties with higher shares of nonessential establishments and workers experience sharp decreases in average hours not at home and the share of individuals away from home eight or more hours per day. This pattern of results

\footnotetext{
${ }^{26}$ We note that this coefficient estimate is only precise at the $10 \%$ level.
} 
suggests that our data can satisfy parallel trends and that FFCRA effects are observable precisely at the effective date. ${ }^{27}$

Unobserved confounders: We conduct a test to explore the importance of unobserved confounders. We first report results excluding time-varying controls and second, we include additional controls (in particular, confirmed COVID-19 cases and deaths). If results change when we include and exclude the time-varying controls, this pattern of results suggests that unobservable confounders do not drive our findings (Altonji, Elder, and Taber 2005). Our coefficient estimates are not appreciably different across specifications (Tables 4 and 5). Falsification: We conduct two falsification tests to further probe our design. First, we estimate Equation (1) using data from 2019: We use the same dates but one year prior to the pandemic. Note that we cannot control for state-level social-distancing policies, as they were not in place in 2019; otherwise the specification is identical to Equation (1). If we were able to replicate our findings in the earlier year, this pattern of results would call to question the internal validity of our design. Results are listed in Table 6: coefficient estimates are generally small in magnitude and not statically different from zero, an exception is one coefficient estimate for average hours not at home that is statistically significant in the opposite direction to our baseline results.

Second, we randomly re-shuffle our treatment variable across counties and dates, and reestimate Equation (1) 100 times, thereby generating 100 placebo estimates. ${ }^{28}$ We compare our main coefficient estimate to the distribution of placebo estimates. If we are capturing the 'true' FFCRA effect rather than some other co-occurring policy or factor that changed on April $1^{\text {st }}$, 2020, then our main coefficient estimate should be an outlier. We report results graphically in Figures 4A and 4B: We present a scatter plot (Panel A) and a histogram (Panel B) of the

\footnotetext{
${ }^{27}$ We show in Section 5.5 that our results are broadly similar when using alternative time windows.

${ }^{28}$ In our re-assignment of the treatment variable, the treatment is assigned to a date.
} 
estimates. In all figures, our main coefficient estimate is an outlier. While we fully

acknowledge that we study a unique time in history, as noted above we are not aware of any

other policy or factor that followed the same rollout. ${ }^{29}$

Assessment of internal validity: We view our testing of the design as providing suggestive

evidence that are main coefficient estimates are not attributable to a violation of parallel trends, unobserved confounders, or some other policy or factor that occurred nationwide on April $1^{\text {st }}$,

2020. However, as has been noted in previous work (Gupta et al. 2020; Brodeur et al. 2020), the

COVID-19 pandemic reflected a unique period in time and, therefore, our study, and all other

COVID-19 studies of which we are aware, are likely vulnerable to bias from unobservable

factors (Goodman-Bacon and Marcus 2020). However, with this caveat in mind, we proceed

with use of the DD-style estimator. In our setting, the policy of interest was implemented

simultaneously across the U.S. so we are not concerned about heterogeneous treatment effects

\footnotetext{
${ }^{29}$ More specifically, there are three federal Acts of which we are aware that became effective during our study period. However, none of these policies provided financial protection for workers who were sick/exposed to COVID-19 or who required time away from work to care for family members due to school closures and so forth. First, the Coronavirus Preparedness and Response Supplemental Appropriations Act (effective March $6^{\text {th }}$, 2020) included \$8.3B to support research and development on vaccines, treatments, and diagnostics (\$3B); public health funding to support preparedness and response efforts (\$2.2B); medical supplies (\$1B); and international COVID-19 funds (\$1.25B). Second, the Coronavirus Aid, Relief, and Economic Security Act or 'CARES' Act (effective March $27^{\text {th }}, 2020$ and paid out over the weekend of April $11^{\text {th }}$ and $12^{\text {th }}, 2020$ ) was a stimulus policy. Individuals with bank accounts could therefore have access to the funds on April $14^{\text {th }}$, although the un-banked would have to wait for their checks to arrive by mail, a minimum of six weeks. As we show in robustness checking, our results are not sensitive to excluding the period when stimulus checks were paid out to the banked population, thus we do not believe that these payments lead to substantial confounding. We have correlated the share of county residents likely to receive a stimulus check with our exposure variable. The correlation is low $(-0.2)$ which further suggests that the policy is not an important confounder. If anything, we suspect that these checks would induce individuals to leave their homes rather than induce them to stay home (e.g., purchase dine-in restaurant meals with additional funds) which would bias our results toward zero. Broadly, the policy included \$300B in cash-payments to individuals (a one-time \$1,200 check), \$260B in unemployment benefits, \$350B to support a payment protection loan program for small businesses; \$500B for loans to corporations; and \$339.8B to state and local governments. Third, the Paycheck Protection Program and Health Care Enhancement Act (effective April 24 ${ }^{\text {th }}, 2020$ ) offered additional funds (\$484B) for the paycheck protection program initiated in the CARES Act, offered additional economic relief in the form of emergency loans to businesses, and provided additional funds for COVID-19 testing. In addition to not directly targeting the outcomes we study, for these policies to lead to bias in our DD-style regression model, the policies would have had to impact counties heterogeneously based on their pre-FFCRA shares of nonessential workers. There is no evidence of which we are aware that these policies had differential effects in this manner. For these reasons, while we cannot rule out some other policy contaminating our findings, our review of concurrent federal policy does not offer any such evidence.
} 
biasing our coefficient estimates (see the work of Goodman-Bacon (2018), Callaway and Sant'Anna (2020), and de Chaisemartin and d'Haultfœuille (2020) for example).

\subsection{Heterogeneity in FFCRA effects across education, race/ethnicity, and industry}

Workers in less desirable jobs are less likely to have access to PSL through their employer, and people of color and with lower levels of education are also less likely to have coverage (Glynn, Boushey, and Berg 2016). Given these differences, the effects of FFCRA could vary across these demographics.

To explore hypotheses related to disparate impacts, we interact the FFCRA with the share of the county that does not have college degree, is African American, is other race, is Hispanic, and works in a blue-collar occupation ${ }^{30}$ using data from the 2014 to 2019 American Community Survey. We de-mean the county-shares for ease of interpretation. Results are reported in Tables 7A and 7B. Broadly, we find some evidence of heterogeneity in FFCRA effects across counties with different demographic profiles. For example, counties with higher shares of non-college educated groups are more impacted by the policy; the elevated impact in such counties is potentially attributable to lower levels of PSL pre-FFCRA for such individuals.

\subsection{Robustness}

We next conduct a series of robustness checks to ensure that our results are stable. We find that our results do not appreciably change across the different specifications and samples; thus, we summarize this analysis and note what we view as particularly important findings. For brevity, we focus on results using our nonessential worker establishment proxy. Results, available on request, are similar using our probabilistic proxy that incorporates employer size.

\footnotetext{
${ }^{30}$ We use service; sales; office and administration support; farming, fishing, and forestry; construction and extraction; installation maintenance and repair; production; and transportation and material moving occupations.
} 
While FFRCA became effective April 1 ${ }^{\text {st }}$, 2020 the DOL did not begin to officially enforce the policy until April $18^{\text {th }}$, 2020. Thus, between April $1^{\text {st }}$ and April $17^{\text {th }}$, employers did not face a penalty for non-enforcement. However, to the best of our knowledge there is no evidence that employers differentially failed to comply with FFCRA during this period. ${ }^{31}$ To explore the empirical importance of enforcement, we include an interaction term between an indicator for the period April $18^{\text {th }}$ to April $30^{\text {th }}$, 2020; this is the period in which we expect the effect of the policy to be most substantial as FFCRA is in place and DOL is actively enforcing the policy. The main effect coefficient estimates are similar to our core results (Tables 3A and 3B), but the interaction terms with the April $18^{\text {th }}$ to April $30^{\text {th }}$, 2020 indicator suggest that FFCRA effects increased when the DOL began to enforce the policy. In particular, post-April $18^{\text {th }}, 2020$ average time not at home decreases by 26.2 minutes while the share of individuals not at home more than eight hours a day increases by 2.3 ppts (Appendix Table 2). ${ }^{32}$ We also define the FFCRA 'effective' date as April $18^{\text {th }}$, 2020 (Appendix Table 3). We test whether the signing of FFCRA by then-President Trump on March $18^{\text {th }}, 2020$ can be viewed as having an impact, perhaps by sending a signal of the importance of staying home while sick or caring for dependents. To implement this test, we treat March $18^{\text {th }}$, 2020 as the 'effective date.' Results (reported in Appendix Table 4) do not suggest strong signaling effects: coefficient estimates are smaller than those reported in Table 3 and are not statistically distinguishable from zero.

We combine SafeGraph data from March $13^{\text {th }}$ to April $30^{\text {th }}$ in 2020 and the equivalent period from 2019, ${ }^{33}$ and conduct an alternative DD model (Appendix Table 5). We do not use variation in nonessential establishments or establishment size in this analysis, instead we conduct

\footnotetext{
${ }^{31}$ See, for example, http://www.wbiw.com/2020/05/13/indiana-trucking-company-pays-back-wages-to-workerdenied-paid-sick-leave-while-experiencing-covid-19-and-seeking-diagnosis/ (last accessed April $7^{\text {th }}$, 2021).

32 We take the sum of the main effect and the interaction term coefficient estimate.

332019 data cover the period from March $15^{\text {th }}$ to May $2^{\text {nd }}$.
} 
a standard DD analysis. In this specification, observations in 2020 comprise the treatment group and observations in 2019 comprise the comparison group; April $1^{\text {st }}$ to April $30^{\text {th }}$ in both years comprise the 'post' period; and observations observed between April $1^{\text {st }}$, 2020 and April 30 ${ }^{\text {th }}$, 2020 comprise the treatment*post indicator. Results were not appreciably different to our main results when using this alternative modelling strategy.

We also apply an interrupted time series analysis (ITSA) to study FFCRA effects (Appendix Table 6). Broadly, ITSA parametrically constructs a counterfactual trend for the U.S. had FFCRA not been adopted, then compares the actual and counterfactual trends to estimate treatment effects. The ITSA results suggest that FFCRA effects lead to a discrete change in social distancing outcomes and that effects may decline over time. For example, at the time of policy adoption, average time away from home decreases by 0.65 hours (38.9 minutes) and this change dissipates by 0.04 hours ( 2.3 minutes) per weekday. We have added a control for the enforcement period in the ITSA model (results available on request). Findings, similar to results listed in Appendix Table 2, suggest that effects are enhanced when the DOL enforces the policy, but after some time to begin to decline. Thus, we do not interpret our findings from our ITSA specification to be discordant with results reported in Appendix Table 2.

For brevity, we report the remaining robustness checks graphically in Appendix Figures 2A (hours away from home) and 2B (share at work). Our results are stable across alternative sample periods. We use a longer pre- and post-FFCRA period: February 1 $1^{\text {st }}, 2020$ through July $17^{\text {th }}, 2020$. We also zero in on the effective date by using a shorter post-treatment time period: March $13^{\text {th }}$, 2020 through April 15 ${ }^{\text {th }}$, 2020. The longer period arguably allows us to explore how effects may vary as time passes and the pandemic proceeds, which is useful because (presumably) as more individuals become sick, they are more likely to take advantage of FFCRA 
benefits and knowledge of the policy among both workers and employers likely increases over time. However, a cost of using the longer study period is that (as noted earlier in the manuscript), many states began re-opening their economies in May, 2020 which could confound effects. On the other hand, while zeroing in on the FFCRA effective date potentially offers the cleanest design (as a shorter study period arguably allows for us to mitigate secular changes in the pandemic in March and April, 2020), we lose the period in which the DOL began to enforce the policy and cannot allow for learning about the policy to occur. We include weekends, we exclude these days in our main analysis as work and school/daycare responsibilities tend to occur during the workweek for most individuals, and we include counties with a pre-FFCRA city- or state-level PSL mandate. We exclude these counties in our main analysis to focus on a homogeneous set of counties, but we note that both types of counties can benefit from FFCRA. Counties without a PSL policy in place can gain some mandated leave (as the DOL explicitly states that FFCRA benefits can be used in conjunction with other benefits) while those with a PSL policy in place can gain additional leave.

As noted earlier in the manuscript, to date the DOL has not provided a specific definition of essential workers. In our main analysis, we rely on a definition developed by Blau, Koebe, and Meyerhofer (2020). Next, we use a definition proposed by Tomer and Kane (2020), and reestimate Equation (1). Result are not appreciably different. We cluster standard errors at the day level, use heteroscedasticity robust standard errors, and apply two-way clustering (county-day). Finally, we also estimate unweighted regression.

\subsection{Extension to confirmed cases}

We next investigate the impact of FFCRA on confirmed COVID-19 cases following Pichler, Wen, and Ziebarth (2020a), although we note that we use a different design. To do so, 
we use data from the Johns Hopkins University Coronavirus Resource Center and construct the logarithm of the number of new cases in the next seven days in each county-day of our study period. Before reporting our main specification, we report an event-study in Figure 5. PreFFCRA counties with different levels of nonessential establishments appear to have followed the same trend in confirmed cases. Table 8 reports results based on Equation (1). We observe a decline of $50.2 \%{ }^{34}$ in the next week's new number of cases post-FFCRA (comparing the counties with the lowest and highest shares of nonessential workers in our sample). While our coefficient estimate implies a large effect size, our confidence intervals are somewhat wide and the upper tail of our 95\% confidence interval implies a 12.6\% decrease. We also note that Pichler et al. document substantial effects: over a 100\% reduction in new daily cases per day. ${ }^{35}$

\section{Discussion}

We offer the first evidence on the impact of paid sick leave on physical mobility (presence at home and at work), a proxy for self-quarantining and family responsibilities, during a global pandemic. These behaviors are critical components of front-line public health efforts to curb disease spread and understanding how policies impact these behaviors is important for public health and economics (Avery et al. 2020). To study this question, we take advantage of a unique confluence of events: We study how a temporary PSL policy in the United States - a large, interconnected economy that lacks universal and nationally mandated PSL - during the COVID-19 pandemic impacted physical mobility within the population. The temporary policy provided a large share of workers with roughly two weeks of fully compensated PSL, with some

\footnotetext{
${ }^{34}$ We calculate this number as follows: percent change $=\exp (-1.103 * 0.689)-1$.

${ }^{35}$ In particular, the sample mean number of new confirmed cases per day per state is 353 (Exhibit 1) and the coefficients estimates from DD regression models range from -375.583 to -494.868 (Exhibit 2). Comparing the coefficient estimates to the sample mean implies relative declines of $106 \%$ to $140 \%$ in new daily confirmed cases per state post-FFCRA for states without a preexisting PSL mandate to those with such a PSL mandate.
} 
workers eligible for substantially more leave. While the federal PSL policy impacted the nation as a whole, differences in eligibility for the benefits differed across U.S. counties, thereby allowing us to estimate a modified difference-in-differences method that exploits heterogeneity in treatment intensity. We combine high frequency data based on more than 20-million cellular devices' (individuals') GPS locations to track physical mobility measured at the county-level with this DD-style approach to estimate FFCRA effects on proxies for social distancing.

Following the federal Act, those individuals are more likely to stay home and less likely to work. In particular, post-FFCRA, comparing the county with the lowest share of nonessential workers to the county with the highest share of nonessential workers in the U.S., the average number of hours away from home decreases by $8.9 \%$ and the share of individuals away from the home for more than eight hours per day declines by $6.9 \%$. Our standard errors are relatively small, and we can rule out effect sizes larger (smaller) than 12.3\% (5.4\%) and 9.4\% (4.4\%) in these outcomes respectively with $95 \%$ confidence. We offer evidence that our research design is valid and show that our results are robust to numerous sensitivity checks.

For the average county, our estimates indicate that FFCRA reduced total hours away from home in the county by approximately 30.7 million hours each day. ${ }^{36}$ Assuming that the reduction in hours away from home came from nonessential workers only indicates that the average nonessential worker in the average county (weighted by population) spent 0.79 fewer hours away from home post FFCRA. Since the FFCRA benefit is limited a fourteen-day allotment of PSL (ten business days), FFCRA may have reduced aggregate time away from home by 307 million hours, or a little under one hour per American. Taken in this light, while

\footnotetext{
${ }^{36}$ We assume that $96 \%$ of Americans owned a cellular device during our study period (https://www.pewresearch.org/internet/fact-sheet/mobile/\#: :text=mobile\%20revolution\%20below.„Mobile\%20phone\%20ownership\%20over\%20time,smartphone\%20ownership\%20conducted\%20in\%202011; last accessed April $7^{\text {th }}$, 2021).
} 
our relative effect sizes (i.e., reported in percent changes) may appear modest in size, the number of hours at home induced by FFCRA appears non-trivial.

We also attempt to assess FFCRA value in terms of reducing disease spread, comparing effectiveness to other policies. We show relative modest declines in remaining at home postpolicy, but large reductions in confirmed cases, similar to Pichler, Wen, and Ziebarth (2020b) who document declines over $100 \%$. Effect sizes, in terms of reduced confirmed cases, appear to be comparable to, and perhaps larger than, other COVID-19 policies such as mask wearing (Lyu and Wehby 2020) and social distancing (Courtemanche et al. 2020).

Our findings contribute to at least two economically and policy relevant literatures. First, our work adds to the literature that explores the impact of PSL mandates in the U.S. Our work complements previous work, which has focused on city and state mandates, by examining an Act that affected the nation. In addition, unlike existing PSL mandates within the U.S., FFCRA is a temporary Act supported by a massive amount of funds (over $\$ 100 \mathrm{~B}$ in federal dollars) that is designed to offer immediate, but tailored, support to workers and their families, and society at large, during an unprecedented outbreak of a highly infectious disease. Second, we add to the recent surge in economic research on government responses to infectious disease (Gupta et al. 2020; Brodeur et al. 2020). A theme in this literature is to study the impact of policies that encourage individuals to adhere to public health practices. In that spirit, we consider how providing workers with financial support impacts self-quarantining.

In summary, we offer crucial timely first evidence on the impact of FFCRA on physical mobility, a proxy for social distancing, a behavior that is critical if the U.S. is to adopt a meaningful public health policy that can mitigate disease spread. Since the aim of this temporary PSL law is to reduce externalities in workplace illness and to reduce caregiver burdens, 
understanding whether workers responded by decreased time in the workplace and increased time at home is vital first step to assessing the effects of the law. 
Table 1. Correlates of county-level nonessential workers

\begin{tabular}{|c|c|c|c|c|}
\hline \multirow{2}{*}{$\begin{array}{l}\text { Variable used to define treatment intensity: } \\
\text { County-level demographics }\end{array}$} & \multicolumn{2}{|c|}{$\begin{array}{c}\text { Nonessential worker } \\
\text { establishments }\end{array}$} & \multicolumn{2}{|c|}{$\begin{array}{c}\text { Nonessential } \\
\text { workers }\end{array}$} \\
\hline & & & & \\
\hline \multirow[t]{2}{*}{ Average age } & $0.004^{* * *}$ & $0.004^{* * *}$ & $0.004 *$ & $0.004^{*}$ \\
\hline & $(0.001)$ & $(0.001)$ & $(0.002)$ & $(0.002)$ \\
\hline \multirow[t]{2}{*}{ Male } & -0.084 & -0.11 & -0.015 & 0.034 \\
\hline & $(0.450)$ & $(0.490)$ & $(0.420)$ & $(0.390)$ \\
\hline \multirow[t]{2}{*}{ African American } & $0.110 * * *$ & $0.086 *$ & $0.220 * * *$ & $0.140 * * *$ \\
\hline & $(0.032)$ & $(0.037)$ & $(0.041)$ & $(0.039)$ \\
\hline \multirow[t]{2}{*}{ Other race } & 0.045 & 0.036 & $0.160 * * *$ & $0.200 * *$ \\
\hline & $(0.026)$ & $(0.069)$ & $(0.043)$ & $(0.074)$ \\
\hline \multirow[t]{2}{*}{ Hispanic } & 0.039 & -0.017 & $0.100 * * *$ & -0.013 \\
\hline & $(0.021)$ & $(0.028)$ & $(0.024)$ & $(0.031)$ \\
\hline \multirow[t]{2}{*}{ Unemployment rate } & -0.370 & -0.410 & $-0.810^{*}$ & $-1.030 * *$ \\
\hline & $(0.300)$ & $(0.330)$ & $(0.330)$ & $(0.340)$ \\
\hline \multirow[t]{2}{*}{ Poverty rate } & -0.130 & -0.080 & -0.260 & -0.160 \\
\hline & $(0.094)$ & $(0.094)$ & $(0.130)$ & $(0.130)$ \\
\hline \multirow[t]{2}{*}{ Population } & 0.0003 & 0.0005 & -0.0001 & 0.0005 \\
\hline & $(0.001)$ & $(0.001)$ & $(0.0004)$ & $(0.0005)$ \\
\hline \multirow[t]{2}{*}{ Average income } & $0.001 * * *$ & $0.001^{* * *}$ & 0.0004 & $0.001 *$ \\
\hline & $(0.0002)$ & $(0.0003)$ & $(0.0004)$ & $(0.0003)$ \\
\hline \multicolumn{5}{|l|}{ County-level weather controls (2019 average) } \\
\hline \multirow[t]{2}{*}{ Precipitation (mm) } & -- & $-0.011 * * *$ & -- & -0.005 \\
\hline & -- & $(0.003)$ & -- & $(0.004)$ \\
\hline \multirow[t]{2}{*}{ Maximum daily temperature $\left({ }^{\circ} \mathrm{F}\right)$} & -- & -0.0009 & -- & $0.005 * * *$ \\
\hline & -- & $(0.001)$ & -- & $(0.001)$ \\
\hline \multirow[t]{2}{*}{ Minimum daily temperature $\left({ }^{\circ} \mathrm{F}\right)$} & -- & 0.002 & -- & $-0.003^{*}$ \\
\hline & -- & $(0.001)$ & -- & $(0.001)$ \\
\hline$N$ (Counties) & 2757 & 2757 & 2757 & 2757 \\
\hline
\end{tabular}

Notes: See text for data sources. Data are weighted by the county population. The unit of observation is a county, there is observation per county. All models are estimated with least squares. Omitted categories for demographics are female and white race. Standard errors are clustered at the county-level and are reported in parentheses. $* * * ; * * ; *=$ statistically different from zero at the $0.1 \%, 1 \%, 5 \%$ level. 
Table 2. Summary statistics pre-FFCRA

\begin{tabular}{lc}
\hline \hline Variable & Mean/proportion \\
\hline County-level outcomes & \\
Average time away from home & 4.540 \\
\% away from home $>8$ hours & 0.286 \\
County-level share of affected workers & \\
Share nonessential worker establishments & 0.651 \\
Share nonessential workers & 0.544 \\
State-level social distancing policies & \\
Public school closure order & 0.796 \\
Stay-at-home order & 0.150 \\
Nonessential business closure & 0.183 \\
Restaurant dining-in prohibited & 0.591 \\
County-level weather controls & 3.881 \\
Precipitation (mm) & 42.13 \\
Maximum daily temperature $\left({ }^{\circ} \mathrm{F}\right)$ & 61.79 \\
Minimum daily temperature $\left({ }^{\circ} \mathrm{F}\right)$ & 36309 \\
\hline$N$ (county $*$ day) & \\
\hline Notes: Data source is SafeGraph Social Distancing Metrics files March $13^{\text {th }}, 2020$ through March $31^{\text {st }}, 2020$. Data \\
are weighted by the county population. The unit of observation is a county in a day.
\end{tabular}


Table 3A. Effect of FFCRA on physical mobility outcomes using a difference-in-differences style model: Baseline specification using the share of nonessential worker establishments to measure treatment intensity

\begin{tabular}{lcc}
\hline \hline Outcome: & Average hours not at home & Away from home $>\mathbf{8}$ hours \\
\hline Post-FFCRA* \% nonessential & $-0.568^{* * *}$ & $-0.027^{* * *}$ \\
& $(0.112)$ & $(0.005)$ \\
Range observed in data & & \\
[1 SD increase] & {$[-0.042]$} & {$[-0.002]$} \\
<10th to 90th percentile $\Delta>$ & $<-0.099>$ & $<-0.005>$ \\
State-level social distancing policies & & \\
Public school closure & $-0.071^{* * *}$ & $-0.004^{* * *}$ \\
& $(0.019)$ & $(0.001)$ \\
Stay-at-home order & $-0.033^{* *}$ & $-0.002^{* *}$ \\
& $(0.010)$ & $(0.001)$ \\
Nonessential business closure & -0.019 & $-0.002^{* *}$ \\
& $(0.012)$ & $(0.001)$ \\
Restaurant dining-in prohibited & -0.015 & -0.000 \\
& $(0.009)$ & $(0.001)$ \\
\hline Pre-FFCRA mean & 4.303 & 0.263 \\
Number of counties in the sample & 2757 & 2757 \\
\hline
\end{tabular}

Notes: Data source is SafeGraph Social Distancing Metrics files March $13^{\text {th }}, 2020$ through April $30^{\text {th }}$, 2020;

weekends are omitted. The unit of observation is a county in a day. Data are weighted by the county population. All models are estimated with least squares and control for weather covariates, county fixed-effects, and date fixedeffects. Standard errors are clustered at the county-level and are reported in parentheses.

$* * * ; * * ; *=$ statistically different from zero at the $0.1 \%, 1 \%, 5 \%$ level.

Table 3B. Effect of FFCRA on physical mobility outcomes using a difference-in-differences style model: Baseline specification using the share of nonessential workers to measure treatment intensity

\begin{tabular}{lcc}
\hline \hline Outcome: & Average hours not at home & Away from home $>\mathbf{8}$ hours \\
\hline Post-FFCRA* \% nonessential & $-0.273^{* *}$ & $-0.011^{*}$ \\
& $(0.089)$ & $(0.004)$ \\
Range observed in data & & \\
[1 SD increase] & {$[-0.031]$} & {$[-0.001]$} \\
<10th to 90th percentile $\Delta>$ & $<-0.075>$ & $<-0.003>$ \\
State-level social distancing policies & & \\
Public school closure & $-0.066^{* * *}$ & $-0.004^{* * *}$ \\
& $(0.019)$ & $(0.001)$ \\
Stay-at-home order & $-0.036^{* * *}$ & $-0.002^{* * *}$ \\
& $(0.010)$ & $(0.000)$ \\
Nonessential business closure & -0.017 & $-0.001^{*}$ \\
& $(0.011)$ & $(0.001)$ \\
Restaurant dining-in prohibited & -0.009 & 0.000 \\
prohibited & $(0.009)$ & $(0.000)$ \\
\hline Pre-FFCRA mean & 4.303 & 0.263 \\
Number of counties in the sample & 2757 & 2757 \\
\hline
\end{tabular}

Notes: Data source is SafeGraph Social Distancing Metrics files March $13^{\text {th }}, 2020$ through April $30^{\text {th }}, 2020$;

weekends are omitted. The unit of observation is a county in a day. Data are weighted by the county population. All models are estimated with least squares and control for weather covariates, county fixed-effects, and date fixedeffects. Standard errors are clustered at the county-level and are reported in parentheses.

$* * * ; * * ; *=$ statistically different from zero at the $0.1 \%, 1 \%, 5 \%$ level. 
Table 3C. Effect of FFCRA on physical mobility outcomes using a difference-in-differences style model: IPV measure imputing both industry and employer size

\begin{tabular}{|c|c|c|}
\hline Outcome: & Average hours not at home & Away from home $>8$ hours \\
\hline \multicolumn{3}{|c|}{ Panel A: Nonessential worker establishments with 50-500 workers used to measure treatment intensity } \\
\hline Post-FFCRA* \% nonessential & $\begin{array}{c}-7.231^{* * *} \\
(1.534)\end{array}$ & $\begin{array}{c}-0.344^{* * *} \\
(0.076)\end{array}$ \\
\hline \multicolumn{3}{|l|}{ Range observed in data } \\
\hline [1 SD increase] & {$[-0.041]$} & [-0.002] \\
\hline$<10$ th to 90 th percentile $\Delta>$ & $<-0.106>$ & $<-0.005>$ \\
\hline \multicolumn{3}{|c|}{ Panel B: Nonessential workers employed at employers with 50-500 workers used to measure treatment } \\
\hline & intensity & \\
\hline Post-FFCRA* \% nonessential & $\begin{array}{l}-0.318 \\
(0.176)\end{array}$ & $\begin{array}{l}-0.020^{*} \\
(0.009)\end{array}$ \\
\hline Range observed in data & & \\
\hline [1 SD increase] & {$[-0.016]$} & {$[-0.001]$} \\
\hline$<10$ th to 90 th percentile $\Delta>$ & $<-0.040>$ & $<-0.002>$ \\
\hline Pre-FFCRA mean & 4.303 & 0.263 \\
\hline Number of counties in the sample & 2757 & 2757 \\
\hline
\end{tabular}

Notes: Data source is SafeGraph Social Distancing Metrics files March $13^{\text {th }}, 2020$ through April 30 ${ }^{\text {th }}, 2020$;

weekends are omitted. Data are weighted by the county population. The unit of observation is a county in a day. All models are estimated with least squares and control for social distancing policies, weather covariates, county fixed-effects, and date fixed-effects. Standard errors are clustered at the county-level and are reported in parentheses.

$* * * ; * ; *=$ statistically different from zero at the $0.1 \%, 1 \%, 5 \%$ level.

Table 4. Effect of FFCRA on physical mobility outcomes using a difference-in-differences style model: Exclude the state-level social distancing policies and weather covariates

\begin{tabular}{|c|c|c|}
\hline Outcome: $\quad$ Panel A: Nonessenti & $\begin{array}{l}\text { Average hours not at home } \\
\text { establishments used to mea }\end{array}$ & Away from home $>8$ hours \\
\hline Post-FFCRA* \% nonessential & $\begin{array}{c}-0.587^{* * *} \\
(0.119)\end{array}$ & $\begin{array}{c}-0.027^{* * *} \\
(0.006)\end{array}$ \\
\hline $\begin{array}{l}\text { Range observed in data } \\
\text { [1 SD increase] } \\
<10 \text { th to } 90 \text { th percentile } \Delta>\end{array}$ & $\begin{array}{l}{[-0.043]} \\
<-0.102>\end{array}$ & $\begin{array}{l}{[-0.002]} \\
<-0.005>\end{array}$ \\
\hline \multicolumn{3}{|c|}{ Panel B: Nonessential workers used to measure treatment intensity } \\
\hline Post-FFCRA* \% nonessential & $\begin{array}{l}-0.282^{* *} \\
(0.093)\end{array}$ & $\begin{array}{l}-0.010^{*} \\
(0.005)\end{array}$ \\
\hline $\begin{array}{l}\text { Range observed in data } \\
\text { [1 SD increase }] \\
<10 \text { th to } 90 \text { th percentile } \Delta>\end{array}$ & $\begin{array}{l}{[-0.032]} \\
<-0.077>\end{array}$ & $\begin{array}{l}{[-0.001]} \\
<-0.003>\end{array}$ \\
\hline $\begin{array}{l}\text { Pre-FFCRA mean } \\
\text { Number of counties in the sample }\end{array}$ & $\begin{array}{l}4.303 \\
2757\end{array}$ & $\begin{array}{l}0.263 \\
2757\end{array}$ \\
\hline
\end{tabular}

Notes: Data source is SafeGraph Social Distancing Metrics files March 13 ${ }^{\text {th }}, 2020$ through April 30 $0^{\text {th }}, 2020$;

weekends are omitted. Data are weighted by the county population. The unit of observation is a county in a day. All models are estimated with least squares and control for social distancing policies, weather covariates, county fixed-effects, and date fixed-effects. Standard errors are clustered at the county-level and are reported in parentheses.

$* * * ; * * ; *$ statistically different from zero at the $0.1 \%, 1 \%, 5 \%$ level. 
Table 5. Effect of FFCRA on physical mobility outcomes using a difference-in-differences style model: Including COVID-19 conemployered cases and deaths

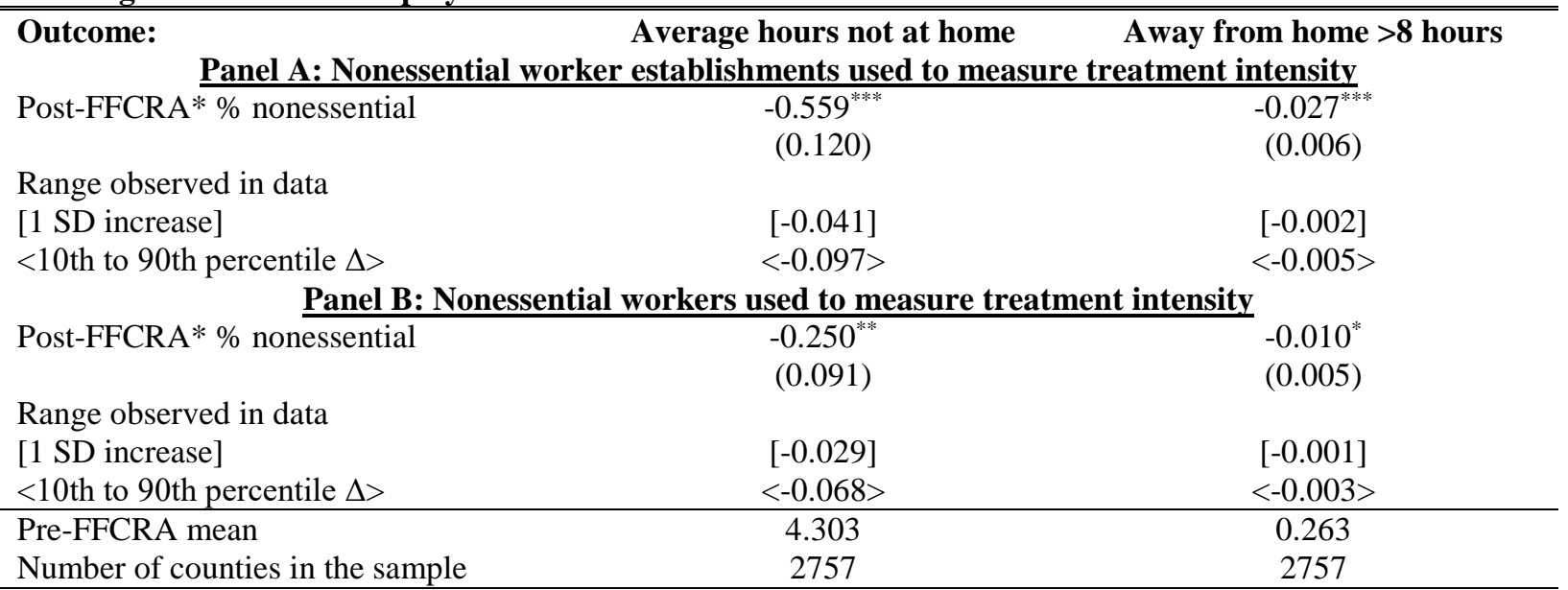

Notes: Data source is SafeGraph Social Distancing Metrics files March 13 ${ }^{\text {th }}, 2020$ through April 30 ${ }^{\text {th }}$, 2020;

weekends are omitted. Data are weighted by the county population. The unit of observation is a county in a day. All models are estimated with least squares and control for social distancing policies, weather covariates, county fixed-effects, and date fixed-effects. Standard errors are clustered at the county-level and are reported in parentheses.

$* * * ; * * * *$ statistically different from zero at the $0.1 \%, 1 \%, 5 \%$ level. 
Table 6. Effect of FFCRA on physical mobility outcomes using a difference-in-differences style model: Falsification testing using 2019 data

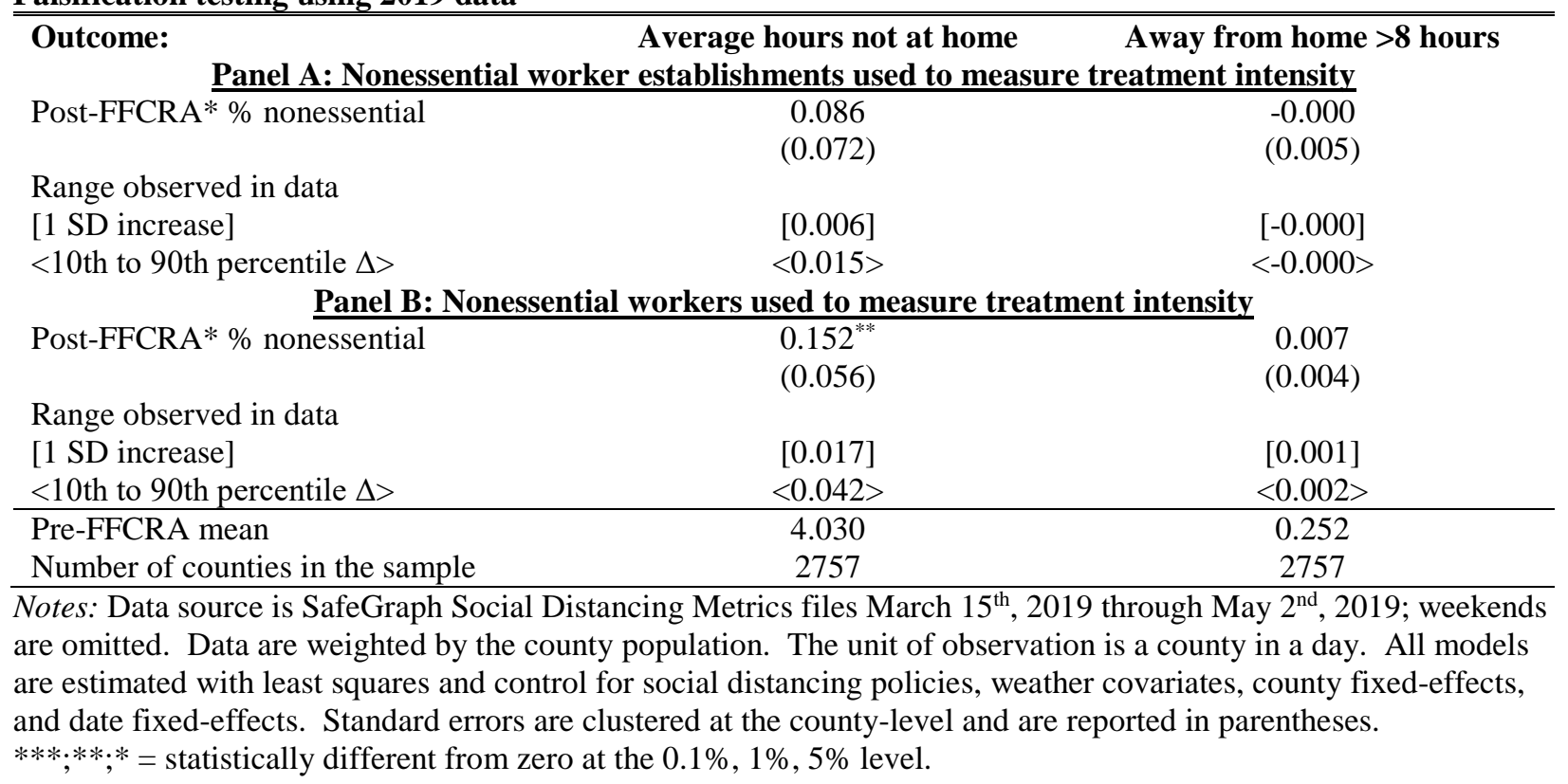


Table 7A. Effect of FFCRA on physical mobility outcomes using a difference-in-differences style model using the share of nonessential worker establishments to define treatment intensity: Allow for interactions between education, race, ethnicity, and blue-collar employment share and FFCRA

\begin{tabular}{|c|c|c|}
\hline Outcome: & Average hours not at home & Away from home $>8$ hours \\
\hline Post-FFCRA* \% nonessential & $\begin{array}{l}-0.022 \\
(0.120)\end{array}$ & $\begin{array}{c}0.001 \\
(0.006)\end{array}$ \\
\hline $\begin{array}{l}\text { Range observed in data } \\
{[1 \text { SD increase }]} \\
<10 \text { th to } 90 \text { th percentile } \Delta>\end{array}$ & $\begin{array}{l}{[-0.003]} \\
<-0.006>\end{array}$ & $\begin{array}{l}{[0.000]} \\
<0.000>\end{array}$ \\
\hline $\begin{array}{l}\text { Post-FFCRA* \% nonessential } \\
\text { *non-college educated } \\
\text { Range observed in data }\end{array}$ & $\begin{array}{l}-11.708^{*} \\
(5.265)\end{array}$ & $\begin{array}{l}-0.800^{* *} \\
(0.279)\end{array}$ \\
\hline $\begin{array}{l}\text { [1 SD increase] } \\
<10 \text { th to } 90 \text { th percentile } \Delta>\end{array}$ & $\begin{array}{l}{[-1.327]} \\
<-3.190>\end{array}$ & $\begin{array}{l}{[-0.091]} \\
<-0.218>\end{array}$ \\
\hline $\begin{array}{l}\text { Post-FFCRA* \% nonessential } \\
\text { *African American } \\
\text { Range observed in data }\end{array}$ & $\begin{array}{l}-1.346 \\
(0.769)\end{array}$ & $\begin{array}{l}-0.098^{*} \\
(0.043)\end{array}$ \\
\hline $\begin{array}{l}\text { Range observed in data } \\
\text { [1 SD increase] } \\
<10 \text { th to } 90 \text { th percentile } \Delta>\end{array}$ & $\begin{array}{l}{[-0.153]} \\
<-0.367>\end{array}$ & $\begin{array}{l}{[-0.011]} \\
<-0.027>\end{array}$ \\
\hline $\begin{array}{l}\text { Post-FFCRA* \% nonessential } \\
\text { *other race }^{\text {oth }}\end{array}$ & $\begin{array}{l}-2.939 \\
(2.450)\end{array}$ & $\begin{array}{l}-0.172 \\
(0.126)\end{array}$ \\
\hline $\begin{array}{l}\text { Range observed in data } \\
\text { [1 SD increase] } \\
<10 \text { th to } 90 \text { th percentile } \Delta>\end{array}$ & $\begin{array}{l}{[-0.333]} \\
<-0.801>\end{array}$ & $\begin{array}{l}{[-0.020]} \\
<-0.047>\end{array}$ \\
\hline $\begin{array}{l}\text { Post-FFCRA* \% nonessential } \\
\text { *Hispanic }\end{array}$ & $\begin{array}{c}0.357 \\
(0.688)\end{array}$ & $\begin{array}{c}0.010 \\
(0.035)\end{array}$ \\
\hline $\begin{array}{l}\text { Range observed in data } \\
\text { [1 SD increase }] \\
<10 \text { th to } 90 \text { th percentile } \Delta>\end{array}$ & $\begin{array}{l}{[0.040]} \\
<0.097>\end{array}$ & $\begin{array}{l}{[0.001]} \\
<0.003>\end{array}$ \\
\hline $\begin{array}{l}\text { Post-FFCRA* \% nonessential } \\
\text { *blue-collar workers } \\
\text { Range observed in data }\end{array}$ & $\begin{array}{c}9.094 \\
(6.185)\end{array}$ & $\begin{array}{l}0.724^{*} \\
(0.323)\end{array}$ \\
\hline $\begin{array}{l}\text { [1 SD increase] } \\
<10 \text { th to } 90 \text { th percentile } \Delta>\end{array}$ & $\begin{array}{l}{[1.031]} \\
<2.478>\end{array}$ & $\begin{array}{l}{[0.082]} \\
<0.197>\end{array}$ \\
\hline $\begin{array}{l}\text { Pre-FFCRA mean } \\
\text { Number of counties in sample }\end{array}$ & $\begin{array}{l}4.303 \\
2757\end{array}$ & $\begin{array}{l}0.263 \\
2757\end{array}$ \\
\hline $\begin{array}{l}\text { Notes: Data source is SafeGraph } \\
\text { weekends are omitted. Data are } \\
\text { All models are estimated with le } \\
\text { fixed-effects, and date fixed-effe } \\
\text { parentheses. We lose one obser } \\
\text { workers in the county and main } \\
\text { request. }\end{array}$ & $\begin{array}{l}\text { thcing Metrics files March } 13^{\text {th }} \text {, } \\
\text { the county population. The un } \\
\text { nd control for social distancing } \\
d \text { errors are clustered at the cou } \\
\text { missing data. We suppress int } \\
\text { No-way interactions for ease of }\end{array}$ & $\begin{array}{l}\text { through April } 30^{\text {th }}, 2020 \text {; } \\
\text { pservation is a county in a day. } \\
\text { es, weather covariates, county } \\
\text { vel and are reported in } \\
\text { ns with the share of blue-collar } \\
\text { ig. Full results available on }\end{array}$ \\
\hline
\end{tabular}


Table 7B. Effect of FFCRA on physical mobility outcomes using a difference-in-differences style model using the share of nonessential workers to define treatment intensity: Allow for interactions between education, race, ethnicity, and blue-collar employment share and FFCRA

\begin{tabular}{|c|c|c|}
\hline Outcome: & Average hours not at home & Away from home $>8$ hours \\
\hline Post-FFCRA* \% nonessential & $\begin{array}{l}-0.134 \\
(0.120)\end{array}$ & $\begin{array}{l}-0.004 \\
(0.006)\end{array}$ \\
\hline $\begin{array}{l}\text { Range observed in data } \\
\text { [1 SD increase] } \\
<10 \text { th to } 90 \text { th } \text { percentile } \Delta>\end{array}$ & $\begin{array}{l}{[-0.010]} \\
<-0.023>\end{array}$ & $\begin{array}{l}{[-0.000]} \\
<-0.001>\end{array}$ \\
\hline $\begin{array}{l}\text { Post-FFCRA* \% nonessential } \\
* \text { *non-college educated }\end{array}$ & $\begin{array}{l}-22.403^{* * *} \\
(5.740)\end{array}$ & $\begin{array}{c}-1.454^{* * *} \\
(0.320)\end{array}$ \\
\hline $\begin{array}{l}\text { Range observed in data } \\
{[1 \text { SD increase }]} \\
<10 \text { th to } 90 \text { th percentile } \Delta>\end{array}$ & $\begin{array}{l}{[-1.650]} \\
<-3.890>\end{array}$ & $\begin{array}{l}{[-0.107]} \\
<-0.252>\end{array}$ \\
\hline $\begin{array}{l}\text { Post-FFCRA* \% nonessential } \\
\text { *African American } \\
\text { Range observed in }\end{array}$ & $\begin{array}{l}-1.666 \\
(0.964)\end{array}$ & $\begin{array}{l}-0.128^{* *} \\
(0.047)\end{array}$ \\
\hline $\begin{array}{l}\text { [1 SD increase] } \\
<10 \text { th to } 90 \text { th percentile } \Delta>\end{array}$ & $\begin{array}{l}{[-0.123]} \\
<-0.289>\end{array}$ & $\begin{array}{l}{[-0.009]} \\
<-0.022>\end{array}$ \\
\hline $\begin{array}{l}\text { Post-FFCRA* \% nonessential } \\
\text { *other race }\end{array}$ & $\begin{array}{l}-2.282 \\
(2.429)\end{array}$ & $\begin{array}{l}-0.196 \\
(0.129)\end{array}$ \\
\hline $\begin{array}{l}\text { Range observed in data } \\
\text { [1 SD increase] } \\
<10 \text { th to } 90 \text { th percentile } \Delta>\end{array}$ & $\begin{array}{l}{[-0.168]} \\
<-0.396>\end{array}$ & $\begin{array}{l}{[-0.014]} \\
<-0.034>\end{array}$ \\
\hline $\begin{array}{l}\text { Post-FFCRA* \% nonessential } \\
{ }^{*} \text { Hispanic }\end{array}$ & $\begin{array}{c}0.856 \\
(0.927)\end{array}$ & $\begin{array}{c}0.016 \\
(0.051)\end{array}$ \\
\hline $\begin{array}{l}\text { Range observed in data } \\
{[1 \text { SD increase] }} \\
<10 \text { th to } 90 \text { th percentile } \Delta>\end{array}$ & $\begin{array}{l}{[0.063]} \\
<0.149>\end{array}$ & $\begin{array}{l}{[0.001]} \\
<0.003>\end{array}$ \\
\hline $\begin{array}{l}\text { Post-FFCRA* \% nonessential } \\
\text { *blue-collar workers }\end{array}$ & $\begin{array}{l}18.664^{*} \\
(7.458)\end{array}$ & $\begin{array}{l}1.274^{* *} \\
(0.406)\end{array}$ \\
\hline $\begin{array}{l}\text { Range observed in data } \\
{[1 \text { SD increase] }} \\
<10 \text { th to } 90 \text { th percentile } \Delta>\end{array}$ & $\begin{array}{l}{[1.374]} \\
<3.241>\end{array}$ & $\begin{array}{l}{[0.094]} \\
<0.221>\end{array}$ \\
\hline $\begin{array}{l}\text { Pre-FFCRA mean } \\
\text { Number of counties in sample }\end{array}$ & $\begin{array}{l}4.303 \\
2757\end{array}$ & $\begin{array}{l}0.263 \\
2757\end{array}$ \\
\hline \multicolumn{3}{|c|}{$\begin{array}{l}\text { Notes: Data source is SafeGraph Social Distancing Metrics files March } 13^{\text {th }}, 2020 \text { through April } 30^{\text {th }}, 2020 \text {; } \\
\text { weekends are omitted. Data are weighted by the county population. The unit of observation is a county in a day. } \\
\text { All models are estimated with least squares and control for social distancing policies, weather covariates, county } \\
\text { fixed-effects, and date fixed-effects. Standard errors are clustered at the county-level and are reported in } \\
\text { parentheses. We lose one observation due to missing data. We suppress interactions with the share of blue-collar } \\
\text { workers in the county and main effects and two-way interactions for ease of viewing. Full results available on } \\
\text { request. } \\
* * * * * * * \text { statistically different from zero at the } 0.1 \%, 1 \%, 5 \% \text { level. }\end{array}$} \\
\hline
\end{tabular}


Table 8. Effect of FFCRA on the logarithm of new weekly conemployered cases in the following seven days using a difference-in-differences style model

\begin{tabular}{lcc}
\hline \hline Treatment intensity defined using: & $\begin{array}{c}\text { Nonessential worker } \\
\text { establishments }\end{array}$ & $\begin{array}{c}\text { Nonessential } \\
\text { workers }\end{array}$ \\
\hline Post-FFCRA* \% nonessential & $-1.103^{*}$ & $-1.148^{* *}$ \\
& $(0.432)$ & $(0.350)$ \\
Range observed in data & {$[-0.081]$} & {$[-0.131]$} \\
[1 SD increase] & $<-0.192>$ & $<-0.314>$ \\
$<10$ th to 90th percentile $\Delta>$ & 10.3 & 10.3 \\
\hline Pre-FFCRA mean (cases per 100,000) & 2757 & 2757 \\
Number of counties in the sample & & \\
\hline Notes: Data source is Johns Hopkins University Coronavirus Resource Center files March $13^{\text {th }}, 2020$ through April \\
$30^{\text {th }}$, 2020; weekends are omitted. The unit of observation is a county in a day. Data are weighted by the county \\
population. All models are estimated with least squares and control for social distancing policies, weather \\
covariates, county fixed-effects, and date fixed-effects. Standard errors are clustered at the county-level and are \\
reported in parentheses. \\
$* * * * * * ; *=$ statistically different from zero at the $0.1 \%, 1 \%, 5 \%$ level. \\
+ We calculate this number as follows: percent change $=\exp \left(-\hat{\beta}^{*} 0.689\right)-1$.
\end{tabular}


Figure 1A. Geographic distribution of nonessential worker establishments and workers across U.S. counties Panel A: Nonessential worker establishments

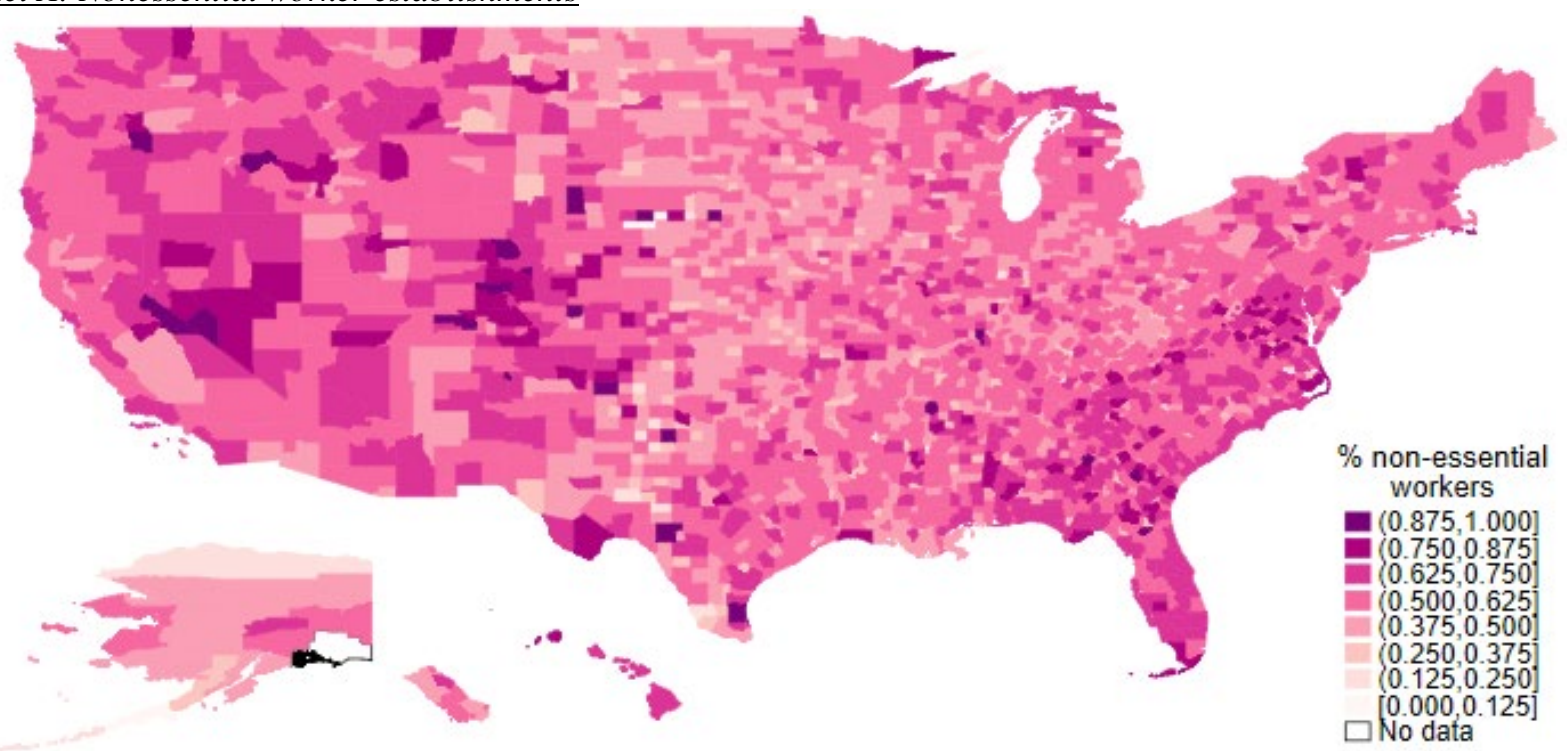

Panel B: Nonessential workers

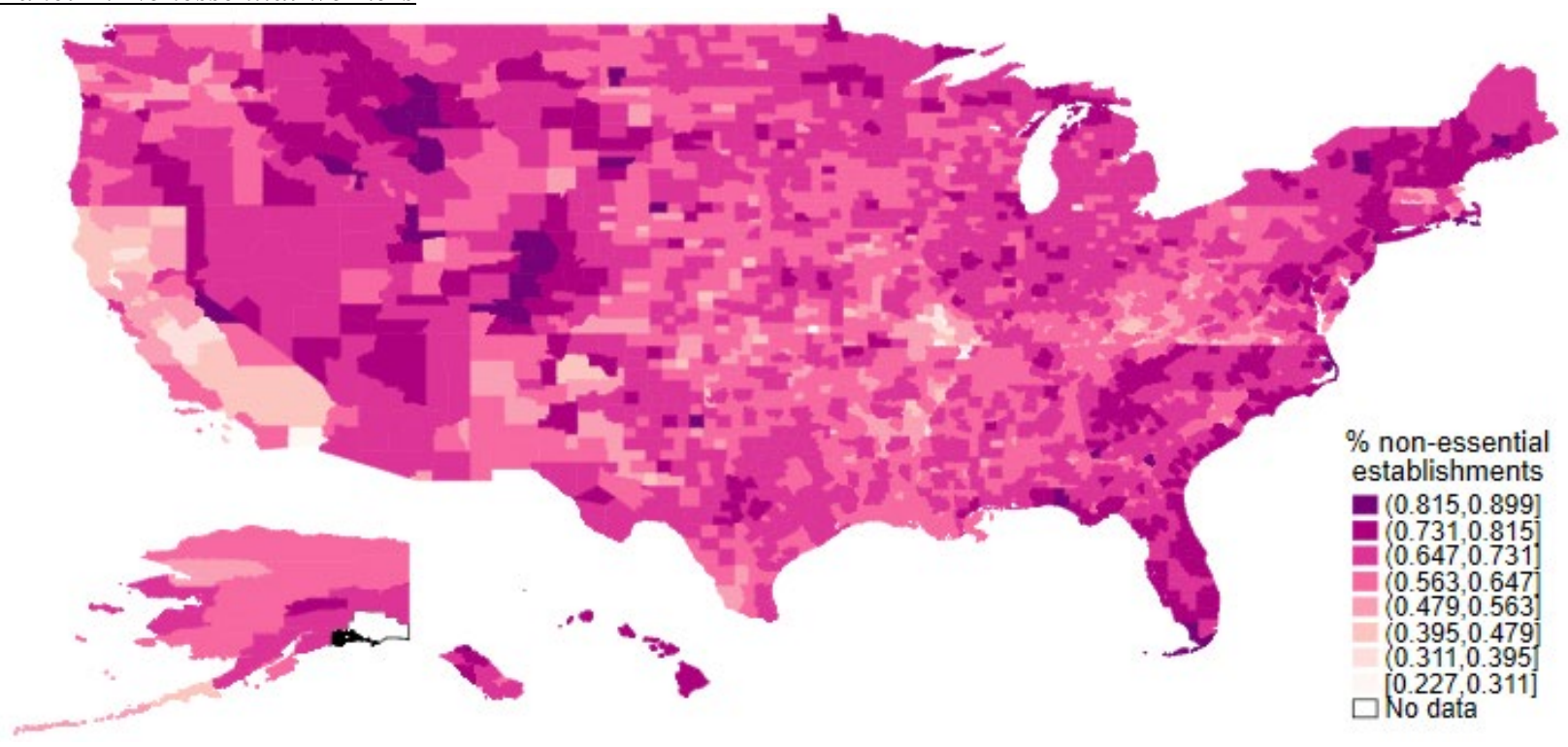

Notes: Data source is Quarterly Census of Employment and Wages 2019. 
Figure 1B. Frequency distribution of nonessential worker establishments and workers across U.S. counties Panel A: Nonessential worker establishments

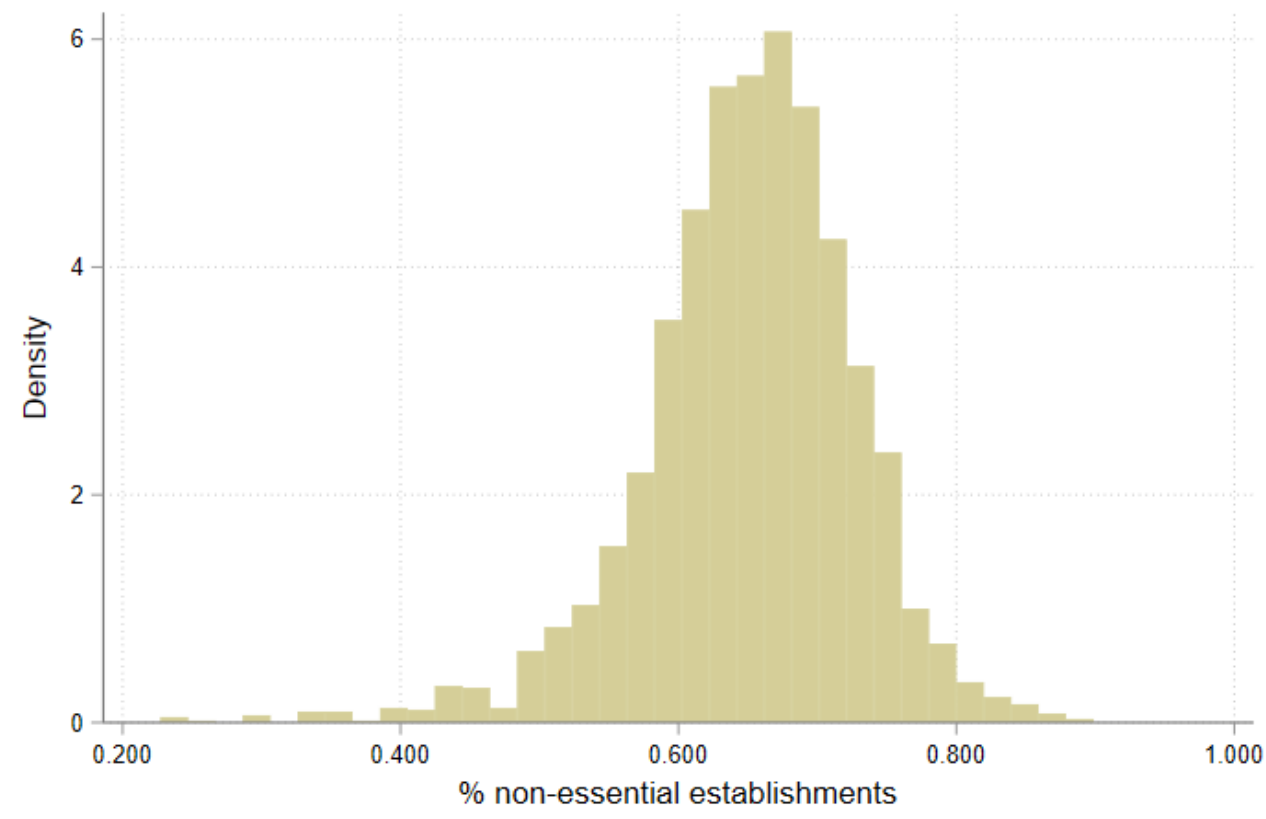

Panel B:Nonessential workers

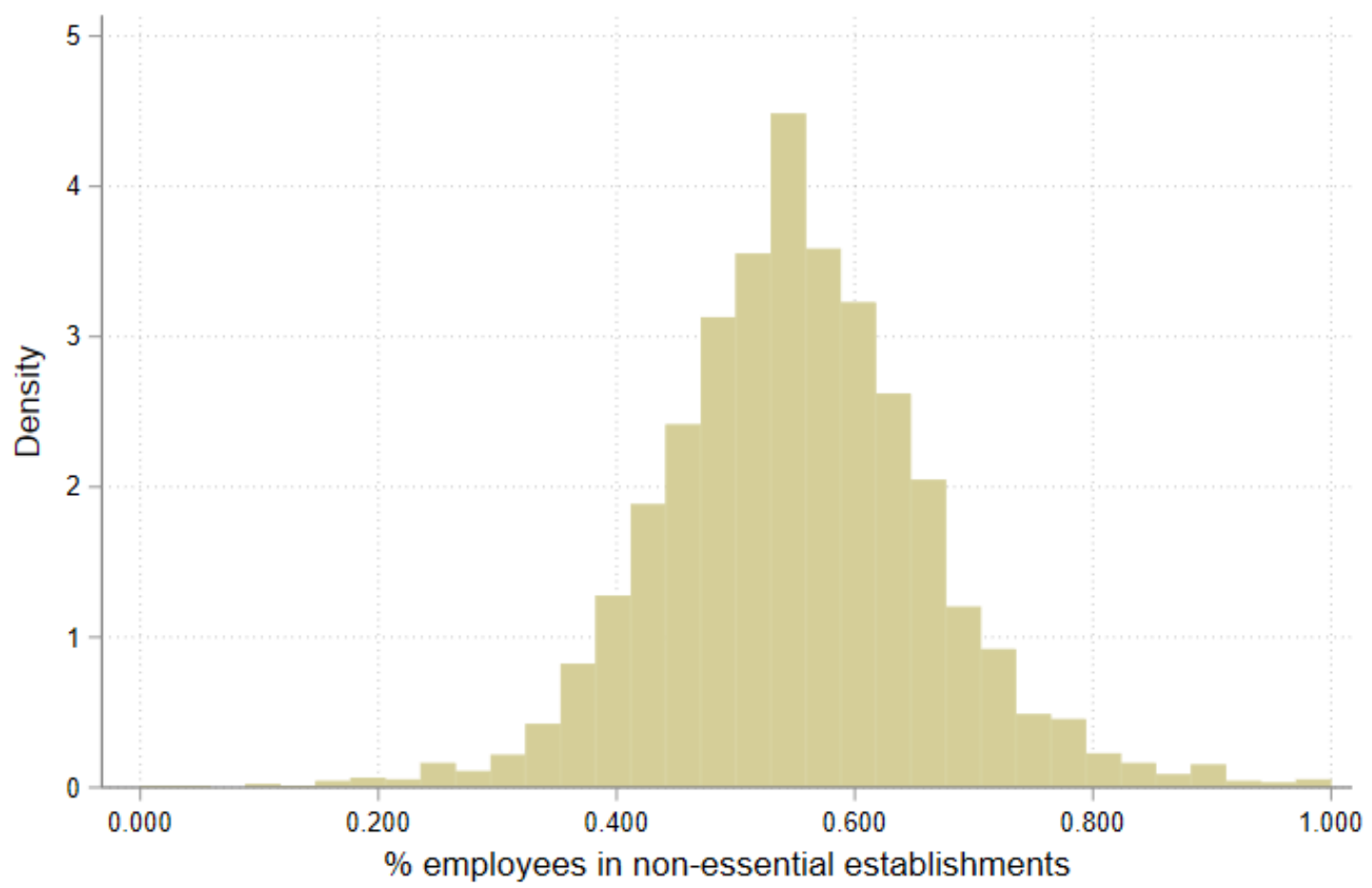

Notes: Data source is Quarterly Census of Employment and Wages 2019 quarter 1. 
Figure 2A. Trends in average hours not at home in 2020 vs. 2019

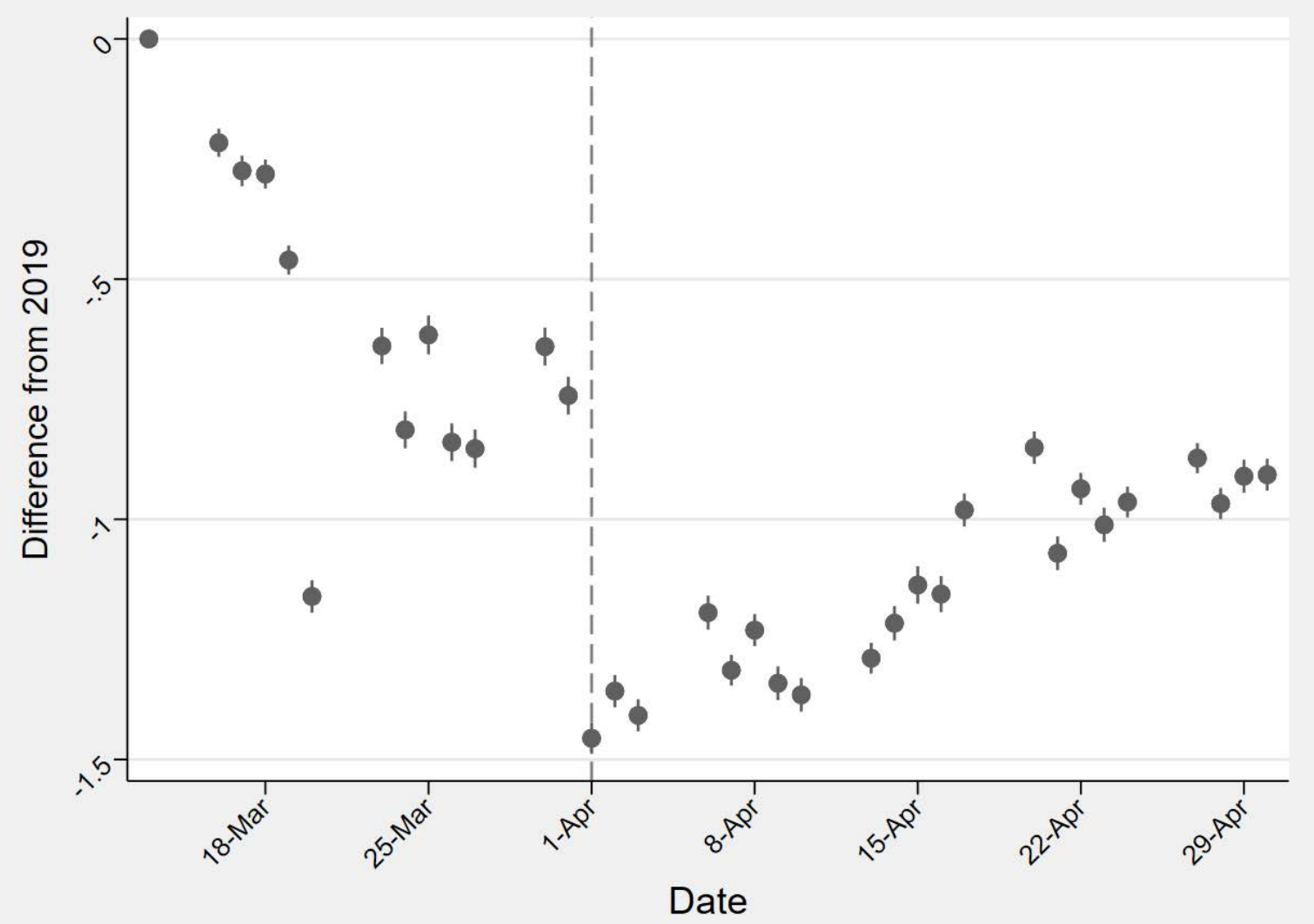

Notes: Data source is SafeGraph Social Distancing Metrics files March 13 $3^{\text {th }}, 2020$ through April 30 ${ }^{\text {th }}, 2020$; weekends are omitted. The unit of observation is a county in a week. Data are demeaned using the grand mean over the full study period. The vertical dashed line indicates April 1, 2020. We conducted testing for a structural break in the data. See text for full details. The F-statistic for a structural break on April $1^{\text {st }}, 2020$ is 4510.1. The maximum F-statistic for a structural break occurs on April $1^{\text {st }}, 2020$ (4510.1). 
Figure 2B. Trends in percent away from home >8 hours per day in 2020 vs. 2019

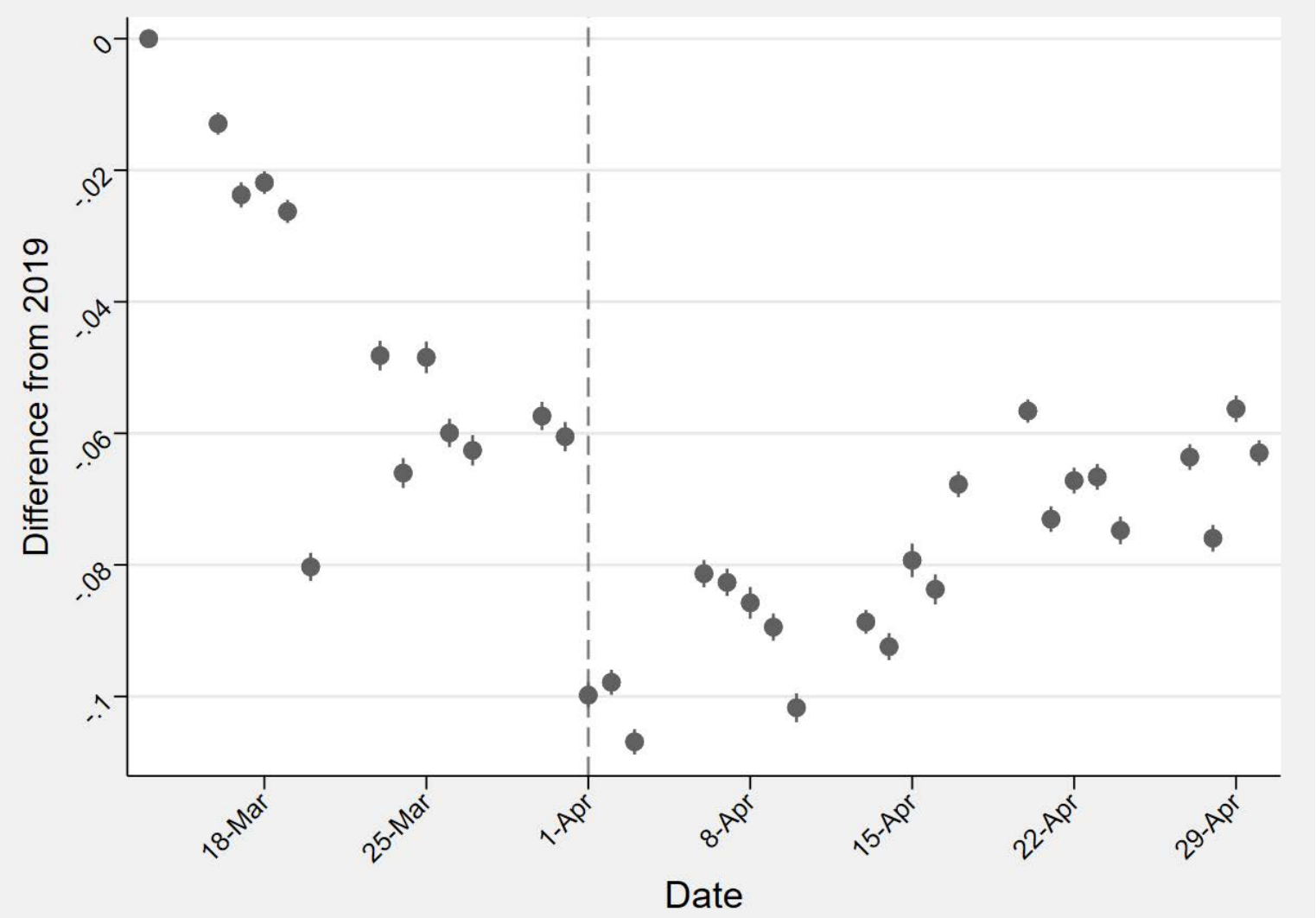

Notes: Data source is SafeGraph Social Distancing Metrics files March 13 $3^{\text {th }}, 2020$ through April 30 ${ }^{\text {th }}, 2020$; weekends are omitted. The unit of observation is a county in a week. Data are demeaned using the grand mean over the full study period. The vertical dashed line indicates April 1, 2020. We conducted testing for a structural break in the data. See text for full details. The F-statistic for a structural break on April $1^{\text {st }}, 2020$ is 6407.4. The maximum F-statistic for a structural break occurs on April $1^{\text {st }}, 2020$ (6407.4). 
Figure 3A. Effect of FFCRA on hours not at home using an event-study design

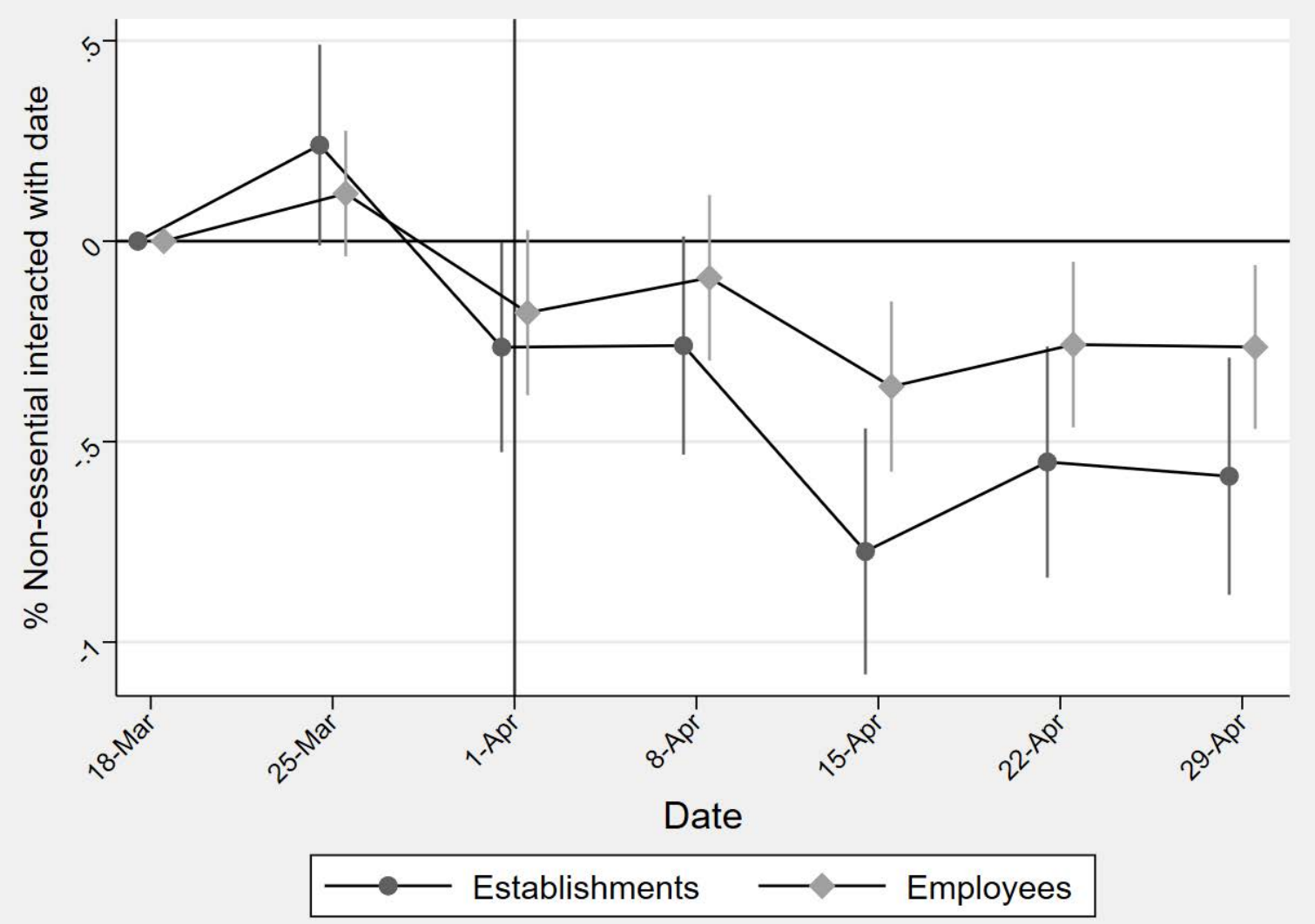

Notes: Data source is SafeGraph Social Distancing Metrics files March 13 $3^{\text {th }}, 2020$ through April 30 ${ }^{\text {th }}, 2020$; weekends are omitted. Data are weighted by the county population. The unit of observation is a county in a day. All models are estimated with least squares and control for social distancing policies, weather covariates, county fixed-effects, and date fixed-effects. Coefficient estimates are reported with black circles. The omitted category is March $13^{\text {th }}, 2020$ to March $24^{\text {th }}$, 2020. 95\% confidence intervals account for within-county clustering and are reported with vertical lines. The vertical dashed line indicates April 1 ${ }^{\text {st }}, 2020$ which is the first day that FFCRA became effective. 
Figure 3B. Effect of FFCRA on percent not at home $>8$ hours per day using an event-study design

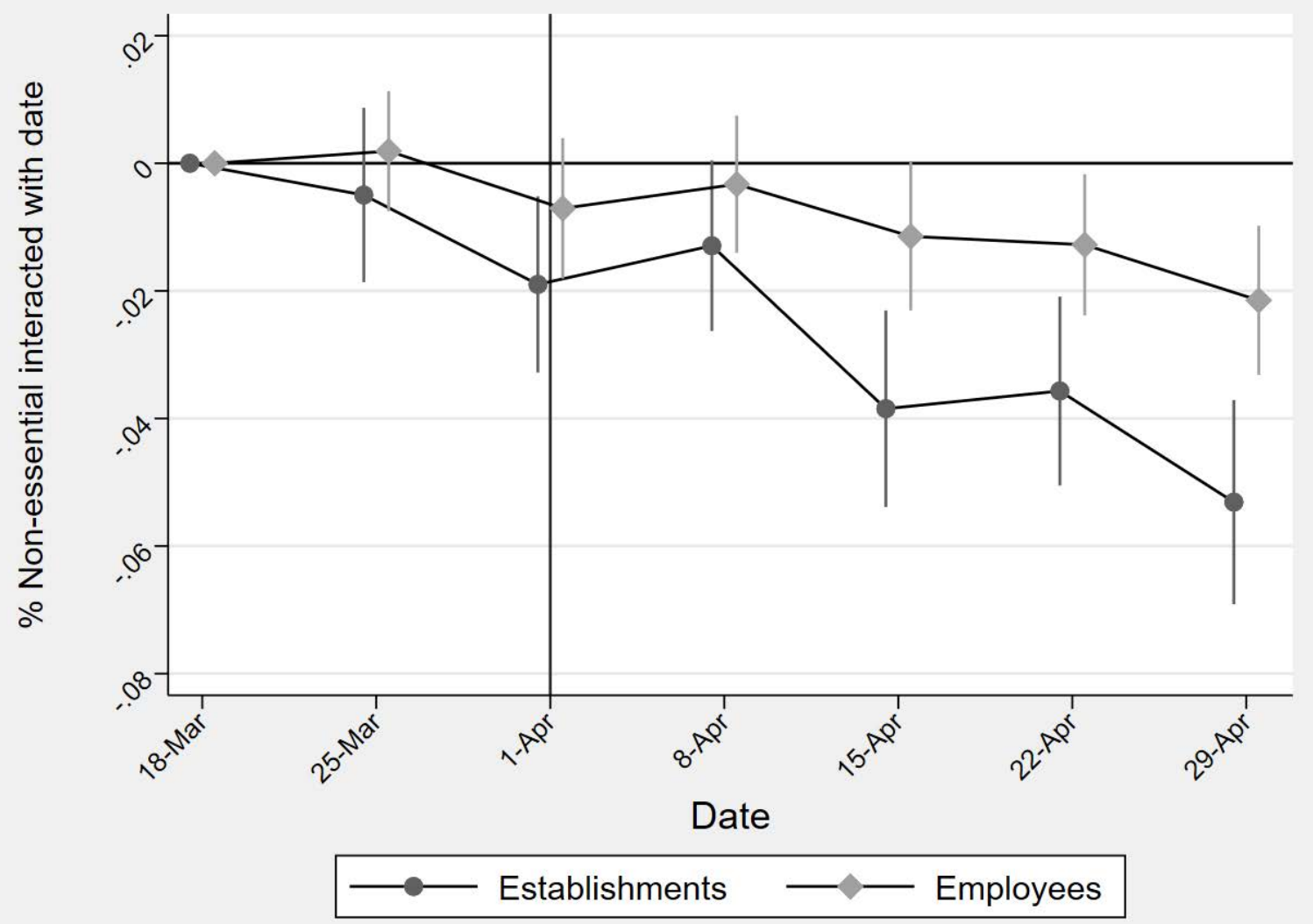

Notes: Data source is SafeGraph Social Distancing Metrics files March 13 $3^{\text {th }}, 2020$ through April 30 ${ }^{\text {th }}, 2020$; weekends are omitted. Data are weighted by the county population. The unit of observation is a county in a day. All models are estimated with least squares and control for social distancing policies, weather covariates, county fixed-effects, and date fixed-effects. Coefficient estimates are reported with black circles. The omitted category is March $13^{\text {th }}, 2020$ to March $24^{\text {th }}$, 2020. 95\% confidence intervals account for within-county clustering and are reported with vertical lines. The vertical dashed line indicates April 1 ${ }^{\text {st }}, 2020$ which is the first day that FFCRA became effective. 
Figure 4A. Effect of FFCRA on average hours not at home using a difference-in-differences style model: Falsification testing

Panel A: Scatter plot (nonessential worker establishments left; nonessential workers right)
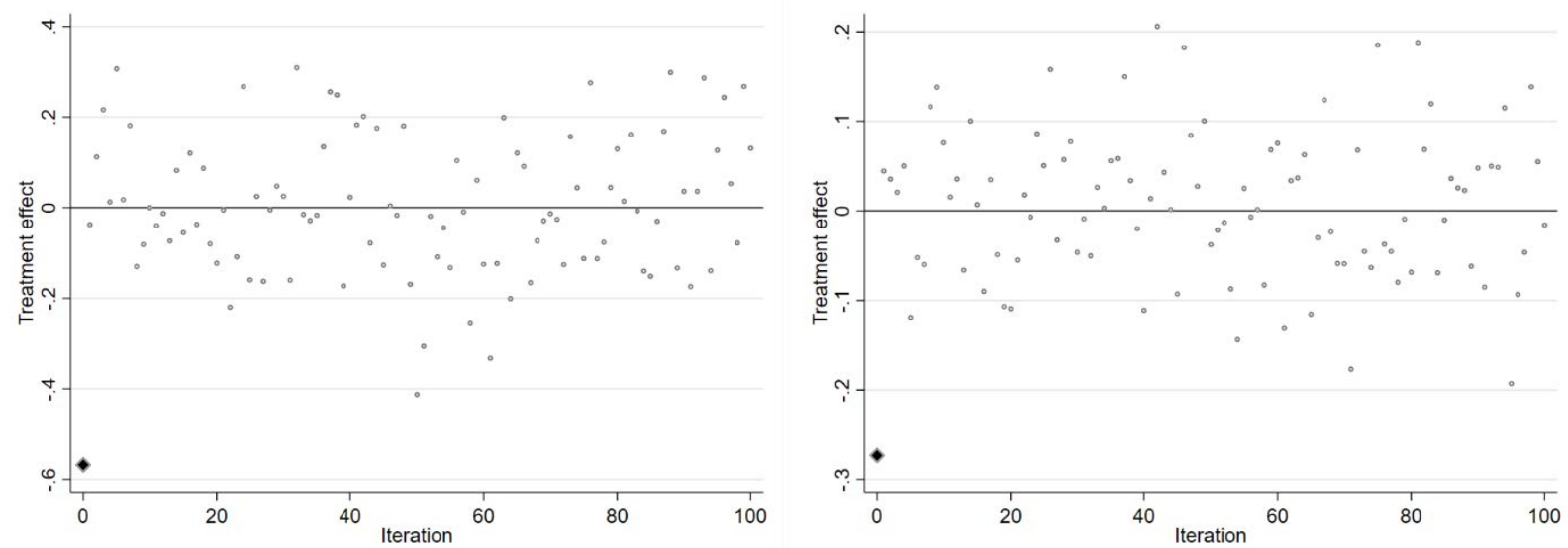

Panel B: Histogram (nonessential worker establishments left; nonessential workers right)
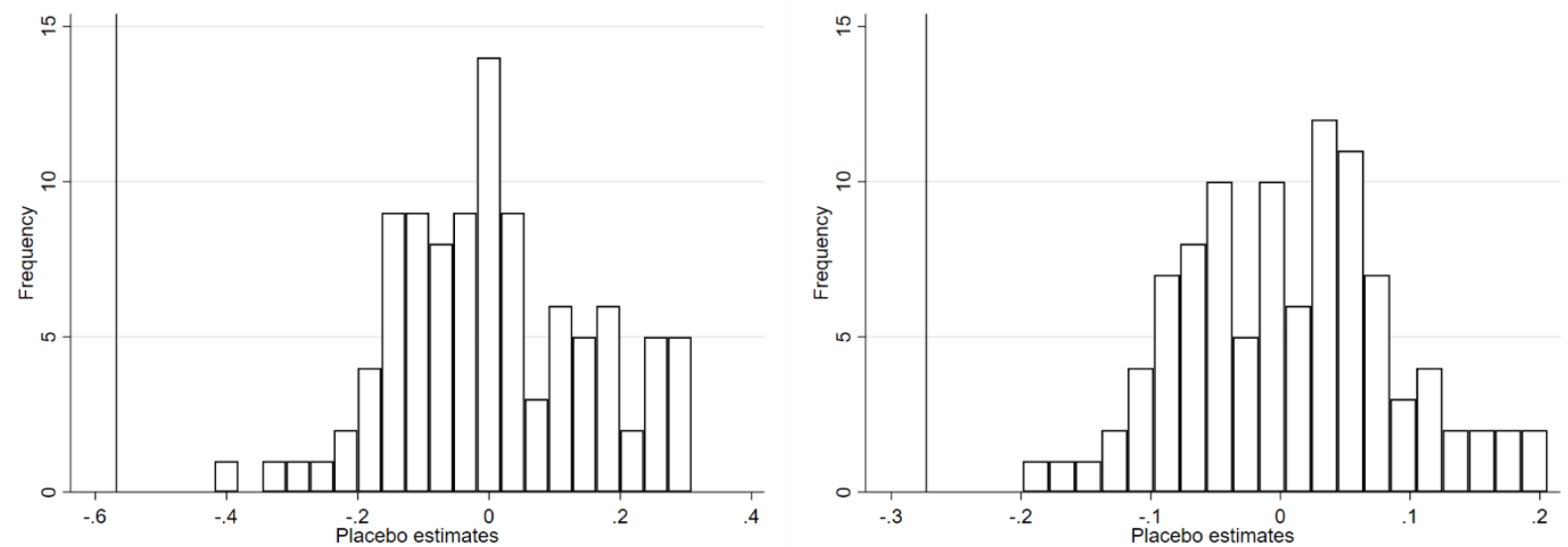

Notes: Data source is SafeGraph Social Distancing Metrics files March $13^{\text {th }}, 2020$ through April $30^{\text {th }}, 2020$; weekends are omitted. The unit of observation is a county in a day. All models are estimated with least squares and control for social distancing policies, weather covariates, county fixed-effects, and date fixed-effects. Panel A: black diamond is the coefficient estimate from our preferred specification and small white circles capture coefficient estimates generated in equation (1) after randomly re-shuffling the treatment variable (Post FFCRA*\% nonessential worker establishments) across counties and dates. 
Figure 4B. Effect of FFCRA on share away from home for $>8$ hours using a difference-in-differences style model: Falsification testing

Panel A: Scatter plot (nonessential worker establishments left; nonessential workers right)
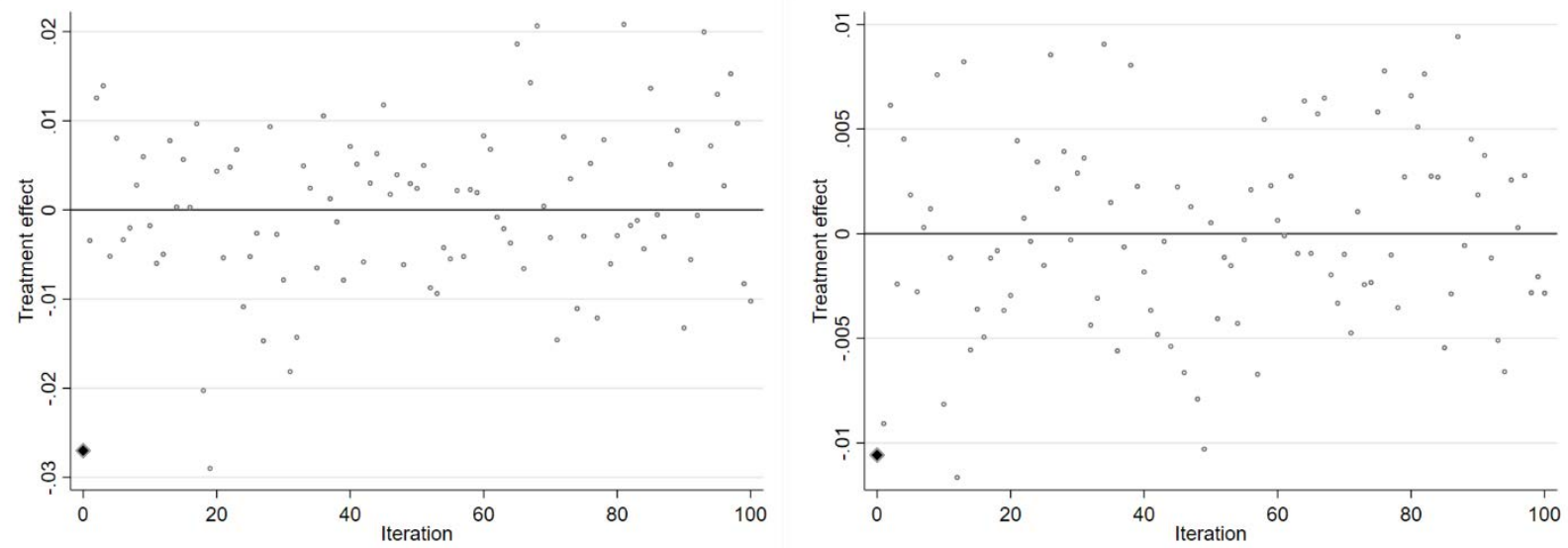

Panel B: Histogram (nonessential worker establishments left; nonessential workers right)
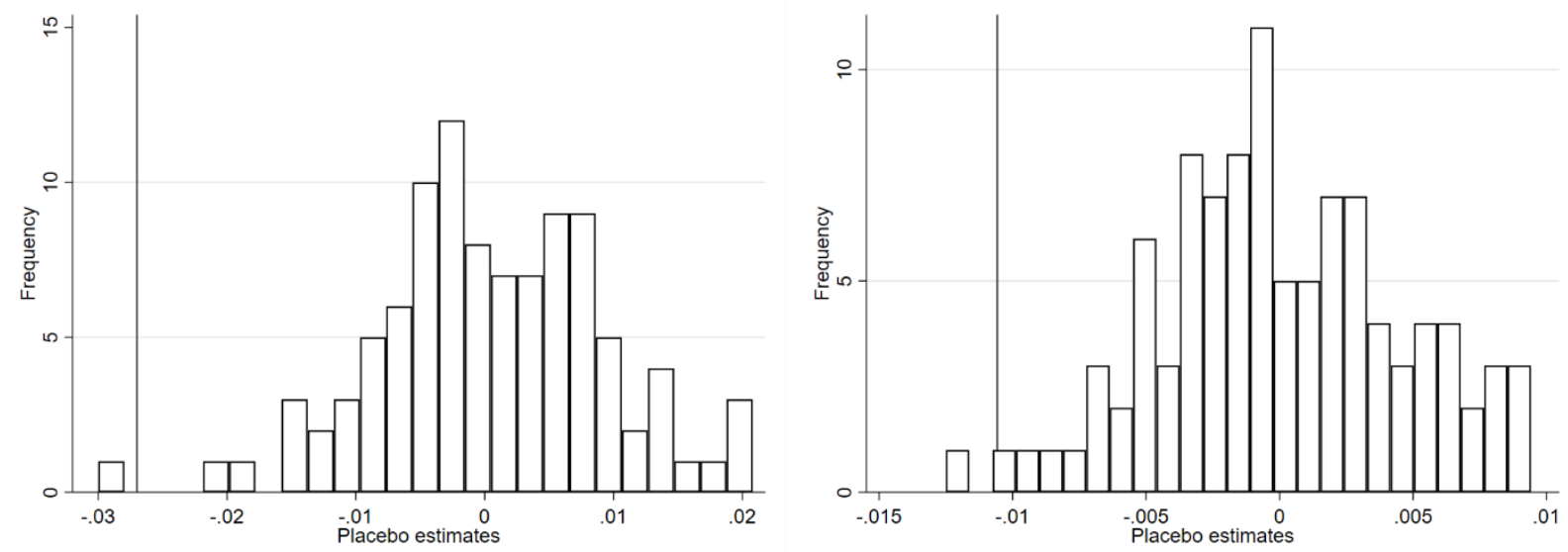

Notes: Data source is SafeGraph Social Distancing Metrics files March $13^{\text {th }}, 2020$ through April $30^{\text {th }}$, 2020; weekends are omitted. The unit of observation is a county in a day. All models are estimated with least squares and control for social distancing policies, weather covariates, county fixed-effects, and date fixed-effects. Panel A: black diamond is the coefficient estimate from our preferred specification and small white circles capture coefficient estimates generated in equation (1) after randomly re-shuffling the treatment variable (Post FFCRA*\% nonessential worker establishments) across counties and dates. 
Figure 5. Effect of FFCRA on the logarithm of new conemployered weekly cases in the following week using an event-study design

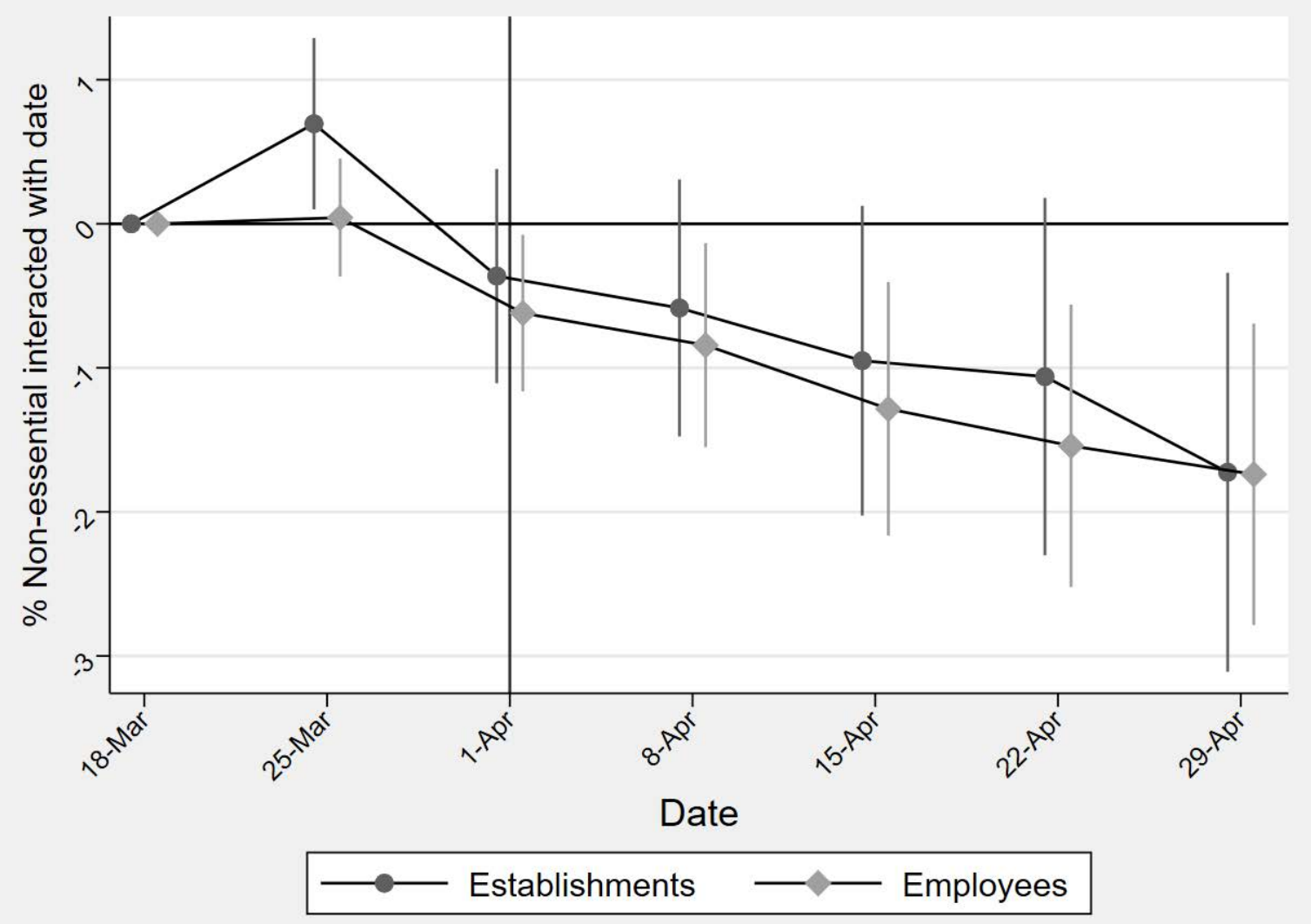

Notes: Data source is Johns Hopkins University Coronavirus Resource Center files March $13^{\text {th }}$, 2020 through April $30^{\text {th }}, 2020$; weekends are omitted. Data are weighted by the county population. The unit of observation is a county in a day. All models are estimated with least squares and control for weather covariates, county fixed-effects, and date fixed-effects. Coefficient estimates are reported with black circles. The omitted category is March $13^{\text {th }}, 2020$ to March $24^{\text {th }}, 2020$. 95\% confidence intervals account for within-county clustering and are reported with vertical lines. The vertical dashed line indicates April 1 ${ }^{\text {st }}, 2020$. 


\section{Data Appendix}

Iterative proportional fitting estimation of county-level exposure to FFCRA PSL

We estimate county-level exposure to FFCRA using data derived from the Quarterly Census of Employment and Wages (QCEW). The Bureau of Labor Statistics (BLS) employs data suppression procedures to ensure that one cannot identify individual employers; as a result, several variables that are of interest to us are suppressed by BLS, including the full distribution of employment by four-digit NAICS code across counties and the size distribution of employers within NAICS-codes and counties. We employ an iterative proportional fitting (IPF) procedure, commonly referred to as RAS within economics, to estimate the number of employers in each industry, county, size cell using a hierarchical procedure exploiting the fact that there is less data suppression at more aggregated levels of the NAICS data.

We proceed in four steps to produce our county level industry-size employment and establishment count data.

Step 1: Complete the national industry-by-size data

We first complete the national data so that we have employment estimates at the industry and size level for all industry and size combinations with a positive number of establishments. The national sector-by-size data are complete, so we IPF procedure estimates of employment at the industry-by-size level within NAICS sectors. In all cases, we are only producing new estimates of employment for cells that were missing in the underlying data. We chose the number of establishments in each industry-size cell as the seed values for our estimates.

\section{Step 2: Constructing state-by-industry-by-size estimates}

In our second step, we work through the QCEW's state-level data to generate a complete table of employment at the industry-size-state level, since the QCEW provides complete establishment data. In order to address suppressed employment data at the industry-state level, we use complete data at the sector-state level to estimate employment values in the missing cells in the industry-state data using establishment counts as seeds and matching employment by state-sector and by sector-size. We then proceed to complete data on statewide employment by size class using the same basic method described previously. With complete state-by-size employment data, we proceed to fill-in missing state-by-sector-by-size employment data. Lastly, we fill in state-by-industry-by-size employment data within each NAICS sector using all available marginal data. This step yields a complete table of establishments and employment at the stateindustry-size level.

\section{Step 3: Complete county-by-industry estimates}

Our third step uses our state-level estimates of employment by industry to complete the countylevel employment by industry data. As outlined in an earlier step, we first estimate, by state, the county-by-sector level employment and then estimate, by state and sector, employment within each county-by-industry cell. In these estimates we seed the IPF procedure with an indicator for 
a positive number of employers in the relevant cell, rather than the number of establishments since we do not (yet) have the employer size distribution in hand.

Step 4: Estimate county-by-size-by industry establishments and employment

Our final step is to infer the within-county size distribution of establishments and employment. These estimates effectively assign, as a baseline, the state-specific establishment size and employment distribution from each industry with then state. These data are then adjusted to ensure that the number of employers in each industry matches our earlier estimates and that total employment matches our earlier estimates, while respecting the industry-by-size distribution of establishments and workers for the entire state. For these analyses, we seed the establishment data with an indicator for the presence of a given industry in the county and the employment seed is the output from the establishment models. 
Appendix Table 1. Localities with pre-FFCRA PSLM

\begin{tabular}{|c|c|}
\hline Type of locality & Specific locality name \\
\hline \multicolumn{2}{|l|}{ States } \\
\hline & Arizona \\
\hline & California \\
\hline & Connecticut \\
\hline & Massachusetts \\
\hline & Maryland \\
\hline & Michigan \\
\hline & New Jersey \\
\hline & Oregon \\
\hline & Rhode Island \\
\hline & Vermont \\
\hline & Washington \\
\hline \multicolumn{2}{|l|}{ Cites and counties } \\
\hline & Berkeley, California \\
\hline & Emeryville, California \\
\hline & Los Angeles, California \\
\hline & Oakland, California \\
\hline & San Diego, California \\
\hline & San Francisco, California \\
\hline & Santa Monica, California \\
\hline & Washington, DC \\
\hline & Chicago, Illinois \\
\hline & Cook County, Illinois \\
\hline & Montgomery County, Maryland \\
\hline & Duluth, Michigan \\
\hline & Minneapolis, Minnesota \\
\hline & Saint Paul, Minnesota \\
\hline & New York City, New York \\
\hline & Westchester County, New York \\
\hline & Philadelphia, Pennsylvania \\
\hline & Pittsburgh, Pennsylvania \\
\hline & Seattle, Washington \\
\hline & Tacoma, Washington \\
\hline & Austin, Texas \\
\hline & Dallas, Texas \\
\hline & San Antonio, Texas \\
\hline
\end{tabular}

Notes: Data source: A Better Balance (2021). 
Appendix Table 2. Effect of FFCRA on physical mobility outcomes using a difference-in-differences style model: Interact an indicator for more than 14 days post-FFCRA with nonessential workers

\begin{tabular}{lcc}
\hline \hline Outcome: & Average hours not at home & Away from home $>\mathbf{8}$ hours \\
\hline Post-FFCRA* \% nonessential & $-0.356^{* * *}$ & $-0.014^{* *}$ \\
& $(0.107)$ & $(0.005)$ \\
Range observed in data & & \\
[1 SD increase] & {$[-0.026]$} & {$[-0.001]$} \\
$<10$ th to 90th percentile $\Delta>$ & $<-0.062>$ & $<-0.002>$ \\
Greater than 14 days Post-FFCRA* \% & $-0.388^{* * *}$ & $-0.024^{* * *}$ \\
nonessential workers & $(0.050)$ & $(0.003)$ \\
Range observed in data & & \\
[1 SD increase] & {$[-0.029]$} & {$[-0.002]$} \\
$<10$ th to 90th percentile $\Delta>$ & $<-0.068>$ & $<-0.004>$ \\
\hline Pre-FFCRA mean & 4.303 & 0.263 \\
Number of counties in the sample & 2757 & 2757 \\
\hline
\end{tabular}

Notes: Data source is SafeGraph Social Distancing Metrics files March $13^{\text {th }}, 2020$ through April $30^{\text {th }}$, 2020; weekends are omitted. Share non-essential worker establishments used to measure treatment intensity. Data are weighted by the county population. The unit of observation is a county in a day. All models are estimated with least squares and control for weather covariates, county fixed-effects, and date fixed-effects. Standard errors are clustered at the county-level and are reported in parentheses.

$* * * ; * * ; *=$ statistically different from zero at the $0.1 \%, 1 \%, 5 \%$ level.

Appendix Table 3. Effect of FFCRA on physical mobility outcomes a difference-in-differences style model: Define April $18^{\text {th }} 2020$ as the FFCRA effective date

\begin{tabular}{lcc}
\hline \hline Outcome: & Average hours not at home & Away from home $>\mathbf{8}$ hours \\
\hline Post-FFCRA* \% nonessential & $-0.474^{* * *}$ & $-0.024^{* * *}$ \\
& $(0.070)$ & $(0.004)$ \\
Range observed in data & & \\
[1 SD increase] & {$[-0.035]$} & {$[-0.002]$} \\
$<10$ th to 90th percentile $\Delta>$ & $<-0.083>-0.004>$ \\
\hline Pre-FFCRA mean & 4.303 & 0.263 \\
Number of counties in the sample & 2757 & 2757 \\
\hline
\end{tabular}

Notes: Data source is SafeGraph Social Distancing Metrics files March $13^{\text {th }}, 2020$ through April 30 ${ }^{\text {th }}, 2020$;

weekends are omitted. Share non-essential worker establishments used to measure treatment intensity. Data are weighted by the county population. The unit of observation is a county in a day. All models are estimated with least squares and control for weather covariates, county fixed-effects, and date fixed-effects. Standard errors are clustered at the county-level and are reported in parentheses. The Department of Labor did not officially began enforcing FFCRA on April 18 $8^{\text {th }}, 2020$.

$* * * ; * * ; *=$ statistically different from zero at the $0.1 \%, 1 \%, 5 \%$ level. 
Appendix Table 4. Effect of FFCRA on physical mobility outcomes a difference-in-differences style model: Define March $18^{\text {th }} 2020$ as the FFCRA effective date

\begin{tabular}{lcc}
\hline \hline Outcome: & Average hours not at home & Away from home $>\mathbf{8}$ hours \\
\hline Post-FFCRA* \% nonessential & -0.346 & -0.008 \\
& $(0.179)$ & $(0.010)$ \\
Range observed in data & {$[-0.026]$} & {$[-0.001]$} \\
[1 SD increase] & $<-0.060>$ & $<-0.001>$ \\
$<10$ th to 90th percentile $\Delta>$ & 4.303 & 0.263 \\
\hline Pre-FFCRA mean & 2757 & 2757 \\
Number of counties in sample & Notes: Data source is SafeGraph Social Distancing Metrics files March 13 ${ }^{\text {th }}, 2020$ through April $30^{\text {th }}, 2020 ;$ \\
weekends are omitted. Share non-essential worker establishments used to measure treatment intensity. Data are \\
weighted by the county population. The unit of observation is a county in a day. All models are estimated with \\
least squares and control for weather covariates, county fixed-effects, and date fixed-effects. Standard errors are \\
clustered at the county-level and are reported in parentheses. President Trump signed FFCRA on March $18^{\text {th }}, 2020$. \\
$* * * ; * * * *$ statistically different from zero at the $0.1 \%, 1 \%, 5 \%$ level.
\end{tabular}

Appendix Table 5. Effect of FFCRA on physical mobility outcomes using difference-in-difference from the comparable date in 2019

\begin{tabular}{lcc}
\hline \hline Outcome: & Average hours not at home & Away from home $>\mathbf{8}$ hours \\
\hline Post-April $1^{\text {st } * 2020}$ & $-0.432^{* * *}$ & $-0.023^{* * *}$ \\
& $(0.026)$ & $(0.001)$ \\
\hline Pre-FFCRA mean & 4.303 & 0.263 \\
Number of counties in sample & 2757 & 2757 \\
\hline
\end{tabular}

Notes: Data source is SafeGraph Social Distancing Metrics files March $13^{\text {th }}, 2020$ through April $30^{\text {th }}, 2020$ and

March $15^{\text {th }}, 2019$ to May $2^{\text {nd }}$, 2019; weekends are omitted. Data are weighted by the county population. The unit of observation is a county in a day. All models are estimated with least squares and control for weather covariates, county fixed-effects, and epidemiological week-by-day-of-week fixed-effects. Epidemiological week-by-day-ofweek fixed-effects control for equivalent dates in 2019 and 2020, so that we compare, for example, the Wednesday of the $13^{\text {th }}$ week of 2020 with the Wednesday of the $13^{\text {th }}$ week of 2019. Standard errors are clustered at the countylevel and are reported in parentheses.

$* * * ; * * * *=$ statistically different from zero at the $0.1 \%, 1 \%, 5 \%$ level. 
Appendix Table 6. Effect of FFCRA on physical mobility outcomes using an interrupted time-series specification

\begin{tabular}{lcc}
\hline Outcome: & Average hours not at home & Away from home $>\mathbf{8}$ hours \\
\hline Post-FFCRA & $-0.649^{* * *}$ & $-0.038^{* * *}$ \\
& $(0.011)$ & $(0.001)$ \\
Post-FFCRA * time & $0.039 * * *$ & $0.003^{* * *}$ \\
& $(0.001)$ & $(0.000)$ \\
Time (relative to April 1, 2020) & $-0.018^{* * *}$ & $-0.002^{* * *}$ \\
& $(0.001)$ & $(0.000)$ \\
\hline Pre-FFCRA mean & 4.303 & 0.263 \\
Number of counties in the sample & 2757 & 2757 \\
\hline Notes: Data source is SafeGraph Social Distancing Metrics files March $13^{\text {th }}, 2020$ through April $30^{\text {th }}, 2020 ;$ \\
weekends are omitted. The unit of observation is a county in a day. All models are estimated with least squares and \\
control for weather covariates, and county fixed-effects. We do not include date fixed-effects in ITSA regression \\
models as we include a linear time trend instead. Standard errors are clustered at the county-level and are reported \\
in parentheses.
\end{tabular}


Appendix Figure 1A. F-statistics for structural breaks for average hours not at home

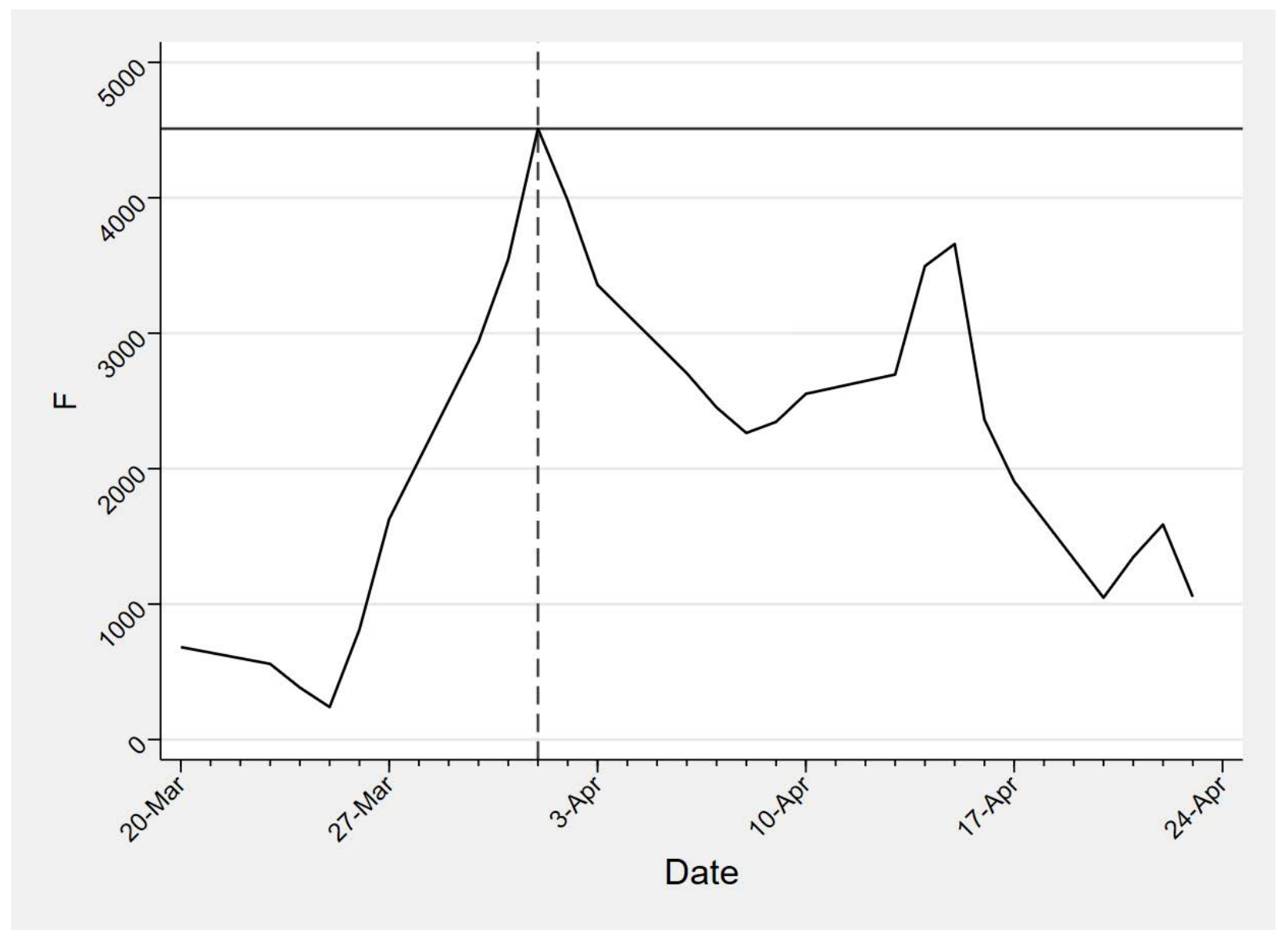

Notes: Data source is SafeGraph Social Distancing Metrics files March $13^{\text {th }}, 2020$ through April 30 ${ }^{\text {th }}, 2020$; weekends are omitted. Lines are the $F$-statistic from a test for a level- and slope-shift in a linear time trend at the indicated date in models controlling for county fixed-effects, weather, and state policies. $F$-statistic based on covariance matrix that is clustered on county. 
Appendix Figure 1B. F-statistics for structural breaks for fraction away from home $>8$ hours

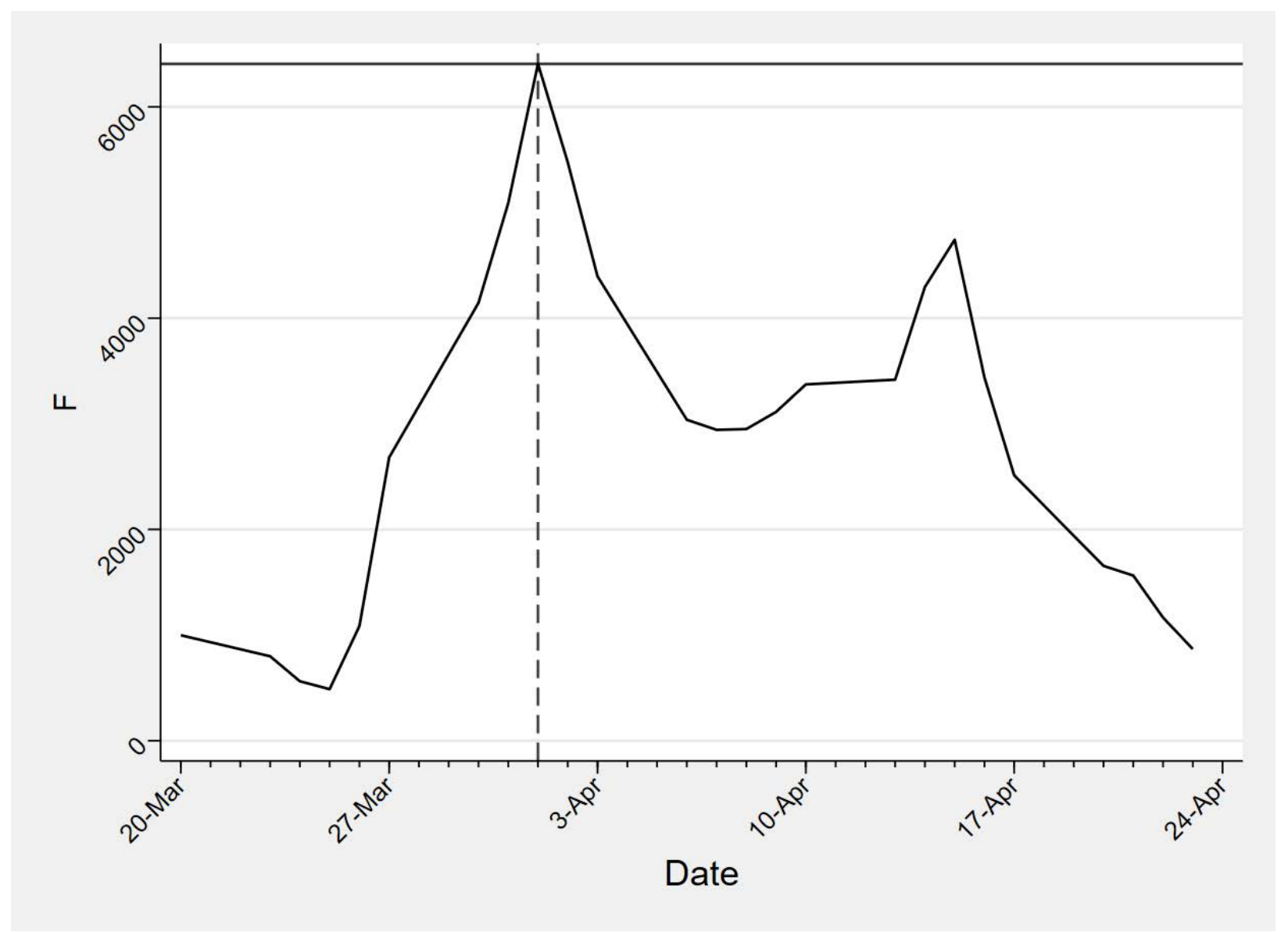

Notes: Data source is SafeGraph Social Distancing Metrics files March $13^{\text {th }}, 2020$ through April 30 ${ }^{\text {th }}, 2020$; weekends are omitted. Lines are the $F$-statistic from a test for a level- and slope-shift in a linear time trend at the indicated date in models controlling for county fixed-effects, weather, and state policies. $F$-statistic based on covariance matrix that is clustered on county. 


\section{Appendix Figure 2A. Specification chart for average hours away from home}

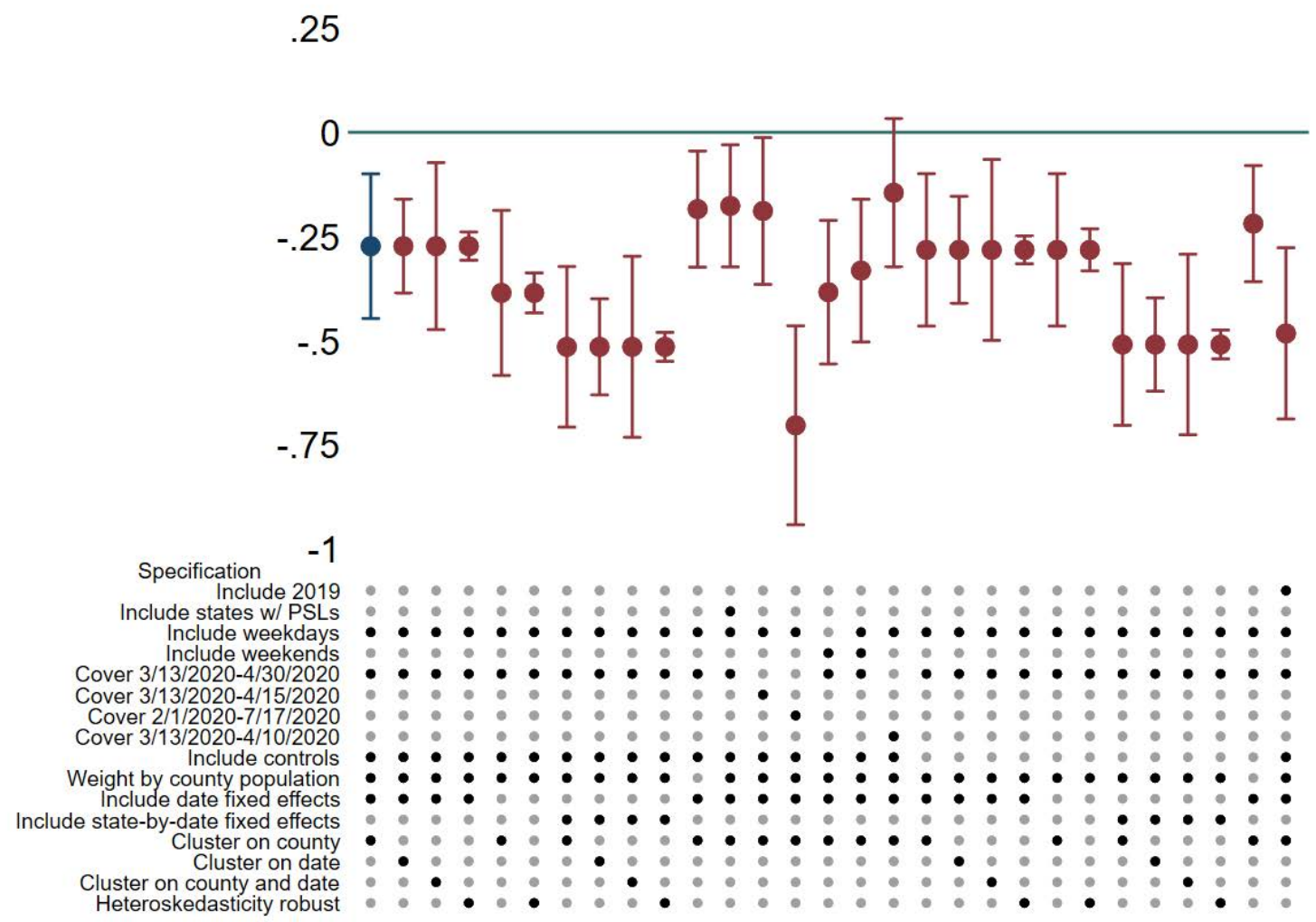

Notes: Blue coefficient estimates and 95\% confidence intervals report main results, red coefficient estimates and 95\% confidence intervals report results based on alternative samples and specifications. Data source is SafeGraph Social Distancing Metrics files March $13^{\text {th }}$, 2020 through April 30 ${ }^{\text {th }}$, 2020; weekends are omitted unless otherwise noted. Share non-essential worker establishments used to measure treatment intensity. Data are weighted by the county population. The unit of observation is a county in a day. All models are estimated with least squares and control for weather covariates, county fixed-effects, and date fixed-effects unless otherwise noted. 95\% confidence intervals account for within-county cluster (unless otherwise noted) are reported. 


\section{Appendix Figure 2B. Specification chart for fraction away from home $>8$ hours}

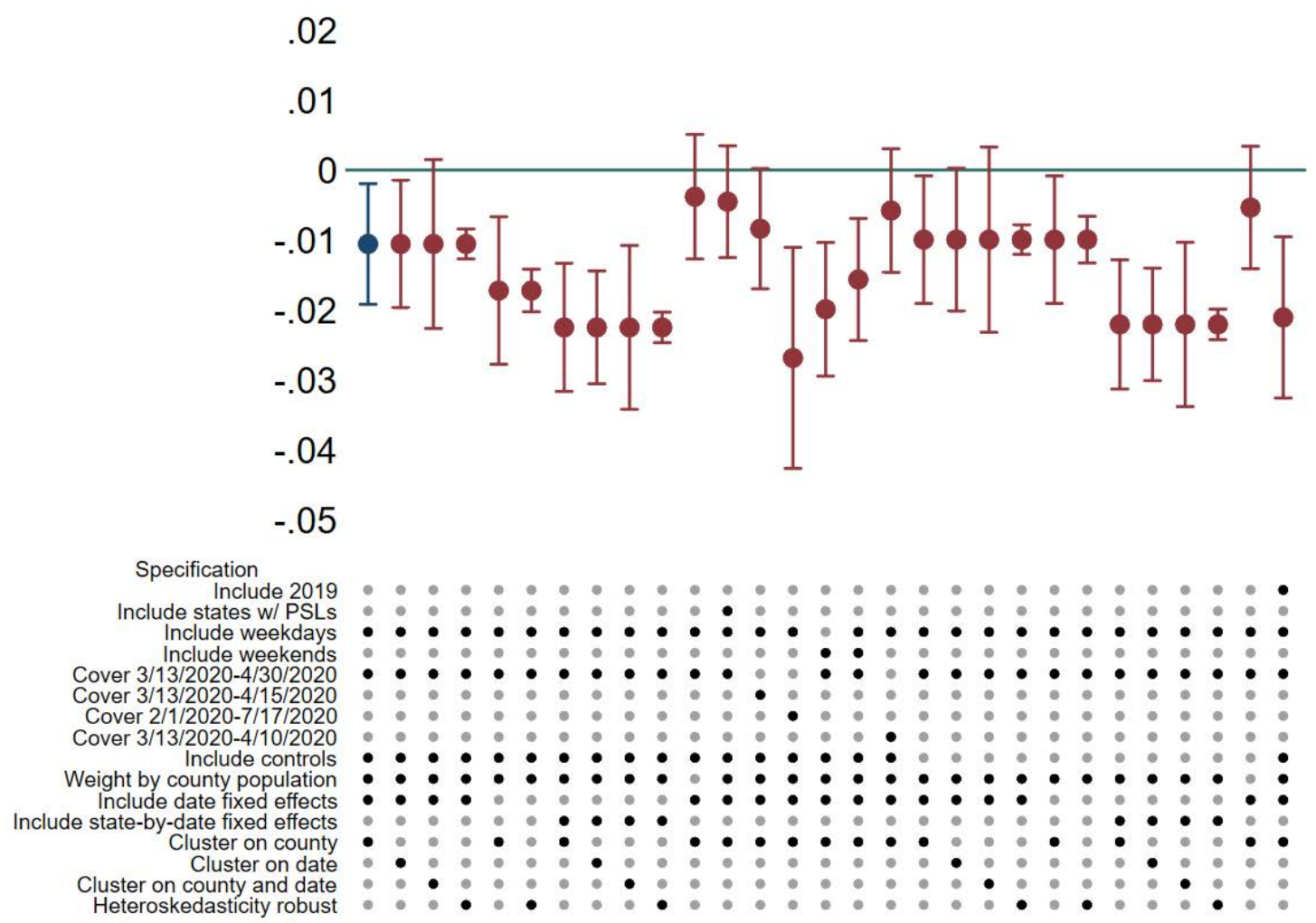

Notes: Blue coefficient estimates and 95\% confidence intervals report main results, red coefficient estimates and 95\% confidence intervals report results based on alternative samples and specifications. Data source is SafeGraph Social Distancing Metrics files March $13^{\text {th }}$, 2020 through April 30 ${ }^{\text {th }}$, 2020; weekends are omitted unless otherwise noted. Share non-essential worker establishments used to measure treatment intensity. Data are weighted by the county population. The unit of observation is a county in a day. All models are estimated with least squares and control for weather covariates, county fixed-effects, and date fixed-effects unless otherwise noted. 95\% confidence intervals account for within-county cluster (unless otherwise noted) are reported. 


\section{References:}

A Better Balance. 2021. Overview of paid sick time laws in the united states. Nashvile, Tennessee: A Better Balance: The Work and Family Legal Center.

Accountemps. 2019. 9 in 10 employees come to work sick, survey shows. Menlo Park, CA: Robert Half.

Adda, J. 2016. "Economic activity and the spread of viral diseases: Evidence from high frequency data." The Quarterly Journal of Economics 131 (2):891-941.

Agüero, J.M., and T. Beleche. 2017. "Health shocks and their long-lasting impact on health behaviors: Evidence from the 2009 h1n1 pandemic in mexico." Journal of Health Economics 54:40-55.

Ahn, T., and A. Yelowitz. 2016. Paid sick leave and absenteeism: The first evidence from the u.S.: Social Science Research Network.

Ali, U., C.M. Herbst, and C.A. Makridis. 2021. "The impact of covid-19 on the us child care market: Evidence from stay-at-home orders." Economics of Education Review 82:102094.

Allcott, H., L. Boxell, J. Conway, M. Gentzkow, M. Thaler, and D. Yang. 2020. "Polarization and public health: Partisan differences in social distancing during the coronavirus pandemic." Journal of Public Economics 191:104254.

Alon, T., M. Doepke, J. Olmstead-Rumsey, and M. Tertilt. 2020. The impact of covid-19 on gender inequality. In National Bureau of Economic Research Working Paper Series. Cambridge, MA: National Bureau of Economic Research.

Alpert, A., D. Powell, and R.L. Pacula. 2018. "Supply-side drug policy in the presence of substitutes: Evidence from the introduction of abuse-deterrent opioids." American Economic Journal: Economic Policy 10 (4):1-35.

Altman, D. 2020. "Understanding the us failure on coronavirus - an essay by drew altman." BMJ 370:m3417.

Altonji, J.G., T.E. Elder, and C.R. Taber. 2005. "Selection on observed and unobserved variables: Assessing the effectiveness of catholic schools." Journal of Political Economy 113 (1):151-184.

Argys, L.M., A.I. Friedson, M.M. Pitts, and D.S. Tello-Trillo. 2020. "Losing public health insurance: Tenncare reform and personal financial distress." Journal of Public Economics 187:104202.

Asfaw, A.G., R.R. Rosa, and R. Pana-Cryan. 2019. "Quickstats: Percentage of currently employed adults who have paid sick leave, by industry-national health interview survey, 2009 and 2018 [USA]." MMWR: Morbidity and mortality weekly report 68 (34):753-753.

Avery, C., W. Bossert, A. Clark, G. Ellison, and S.F. Ellison. 2020. Policy implications of models of the spread of coronavirus: Perspectives and opportunities for economists. In National Bureau of Economic Research Working Paper Series. Cambridge, MA: National Bureau of Economic Research.

Bacharach, M. 1965. "Estimating nonnegative matrices from marginal data." International Economic Review 6 (3):294-310.

Beheshti, D. 2019. "Adverse health effects of abuse-deterrent opioids: Evidence from the reformulation of oxycontin." Health Economics 28 (12):1449-1461.

Bertrand, M., E. Duflo, and S. Mullainathan. 2004. "How much should we trust differences-indifferences estimates?" The Quarterly Journal of Economics 119 (1):249-275. 
Blau, F.D., J. Koebe, and P.A. Meyerhofer. 2020. Who are the essential and frontline workers? : National Bureau of Economic Research.

Böckerman, P., O. Kanninen, and I. Suoniemi. 2018. "A kink that makes you sick: The effect of sick pay on absence." Journal of Applied Econometrics 33 (4):568-579.

Bodas, M., and K. Peleg. 2020. "Self-isolation compliance in the covid-19 era influenced by compensation: Findings from a recent survey in israel: Public attitudes toward the covid19 outbreak and self-isolation: A cross sectional study of the adult population of israel." Health Affairs 39 (6):936-941.

Brodeur, A., D.M. Gray, A. Islam, and S. Bhuiyan. 2020. A literature review of the economics of covid-19. In IZA Discussion paper. Bonn, Germany: Institute of Labor Economics.

Callaway, B., and P.H.C. Sant’Anna. 2020. "Difference-in-differences with multiple time periods." Journal of Econometrics.

Callison, K., and M. Pesko. 2020. "The effect of paid sick leave mandates on coverage, work absences, and presenteeism." Journal of Human Resources Forthcoming.

Colla, C.H., W.H. Dow, A. Dube, and V. Lovell. 2014. "Early effects of the san francisco paid sick leave policy." American Journal of Public Health 104 (12):2453-2460.

Committee for a Responsible Federal Budget. 2020. Families first coronavirus response act will cost \$192 billion. Washington, DC: Committee for a Responsible Federal Budget,.

Courtemanche, C., J. Marton, B. Ukert, A. Yelowitz, and D. Zapata. 2017. "Early impacts of the affordable care act on health insurance coverage in medicaid expansion and nonexpansion states." Journal of Policy Analysis and Management 36 (1):178-210.

Courtemanche, C.J., J. Garuccio, A. Le, J.C. Pinkston, and A. Yelowitz. 2020. "Strong social distancing measures in the united states reduced the covid-19 growth rate." Health Affairs 39 (7):1237-1246.

Cronin, C.J., and W.N. Evans. 2020. Private precaution and public restrictions: What drives social distancing and industry foot traffic in the covid-19 era? Cambridge, MA: National Bureau of Economic Research.

de Chaisemartin, C., and X. d'Haultfœuille. 2020. "Two-way fixed effects estimators with heterogeneous treatment effects." American Economic Review 110 (9):2964-96.

De Paola, M., V. Scoppa, and V. Pupo. 2014. "Absenteeism in the italian public sector: The effects of changes in sick leave policy." Journal of Labor Economics 32 (2):337-360.

Department of Labor. 2020a. Families first coronavirus response act: Employee paid leave rights. Washington, DC: Department of Labor.

- 2020b. Families first coronavirus response act: Questions and answers. Washington, DC: Department of Labor.

Federal Register. 2020. Paid leave under the families first coronavirus response act. Washington, DC: National Archives.

Finkelstein, A. 2007. "The aggregate effects of health insurance: Evidence from the introduction of medicare." The Quarterly Journal of Economics 122 (1):1-37.

Glynn, S.J. 2020. Coronavirus paid leave exemptions exclude millions of workers from coverage. Washington, DC: Center for American Progress.

Glynn, S.J., H. Boushey, and P. Berg. 2016. Who gets time off? Washington, DC: Center for American Progress.

Goodman-Bacon, A. 2018. Difference-in-differences with variation in treatment timing. In National Bureau of Economic Research Working Paper Series. Cambridge, MA: National Bureau of Economic Research. 
Goodman-Bacon, A., and J. Marcus. 2020. Using difference-in-differences to identify causal effects of covid-19 policies. In Social Science Research Network Working Paper Series: Social Science Research Network.

Gould, E. 2020. State of working america wages 2019. Washington, DC: Economic Policy Institute.

Gruber, J. 1994. "The incidence of mandated maternity benefits." The American Economic Review:622-641.

Gupta, S., T.D. Nguyen, F.L. Rojas, S. Raman, B. Lee, A. Bento, K.I. Simon, and C. Wing. 2020. Tracking public and private responses to the covid-19 epidemic: Evidence from state and local government actions. National Bureau of Economic Research.

Henrekson, M., and M. Persson. 2004. "The effects on sick leave of changes in the sickness insurance system." Journal of Labor Economics 22 (1):87-113.

Internal Revenue Service. 2020. Covid-19-related tax credits for required paid leave provided by small and midsize businesses frequently asked questions. Washtington, DC: Internal Revenue Service.

Kumar, S., S.C. Quinn, K.H. Kim, L.H. Daniel, and V.S. Freimuth. 2012. "The impact of workplace policies and other social factors on self-reported influenza-like illness incidence during the 2009 h1n1 pandemic." American Journal of Public Health 102 (1):134-140.

Lyu, W., and G.L. Wehby. 2020. "Community use of face masks and covid-19: Evidence from a natural experiment of state mandates in the us: Study examines impact on covid-19 growth rates associated with state government mandates requiring face mask use in public." Health Affairs 39 (8):1419-1425.

Maclean, J.C., S. Pichler, and N.R. Ziebarth. 2020. Mandated sick pay: Coverage, utilization, and welfare effects. National Bureau of Economic Research.

NPR, Kaiser Family Foundation, and Harvard School of Public Health. 2008. Health care and the economy in two swing states: A look at ohio and florida. Washington, DC: Kaiser Family Foundation.

Park, S., and D. Powell. 2021. "Is the rise in illicit opioids affecting labor supply and disability claiming rates?" Journal of Health Economics:102430.

Pichler, S., K. Wen, and N.R. Ziebarth. 2020a. "Covid-19 emergency sick leave has helped flatten the curve in the united states." Health Affairs 39 (12):2197-2204.

Pichler, S., K. Wen, and N.R. Ziebarth. 2020b. Positive health externalities of mandating paid sick leave.

Pichler, S., and N.R. Ziebarth. 2017. "The pros and cons of sick pay schemes: Testing for contagious presenteeism and noncontagious absenteeism behavior." Journal of Public Economics 156:14-33.

Powell, D., A. Alpert, and R.L. Pacula. 2019. "A transitioning epidemic: How the opioid crisis is driving the rise in hepatitis c." Health Affairs 38 (2):287-294.

Powell, D., and R.L. Pacula. 2021. "The evolving consequences of oxycontin reformulation on drug overdoses." American Journal of Health Economics 7 (1):000-000.

Puhani, P.A., and K. Sonderhof. 2010. "The effects of a sick pay reform on absence and on health-related outcomes." Journal of Health Economics 29 (2):285-302.

Raifman, J. 2020. Covid-19 us state policy database. Boston, MA: Boston University.

Ruggles, S., S. Flood, S. Foster, R. Goeken, J. Pacas, M. Schouweiler, and M. Sobek. 2021. Ipums USA: Version 11.0. edited by IPUMS. Minneapolis, MN. 
Schneider, D. 2020. "Paid sick leave in washington state: Evidence on employee outcomes, 2016-2018." American Journal of Public Health 110 (4):499-504.

Scognamiglio, A. 2020. "Paid sick leave and employee absences." LABOUR 34 (3):305-322.

Smith, T. 2008. Paid sick days: A basic labor standard for the 21st century Chicago, IL: National Opinion Research Center at the University of Chicago.

Stearns, J., and C. White. 2018. "Can paid sick leave mandates reduce leave-taking?" Labour Economics 51:227-246.

Susser, P., and N. Ziebarth. 2016. "Profiling the us sick leave landscape." Labor: Public Policy \& Regulation eJournal.

The Council of State Governments. 2020. State reopen plans. Lexington, KY: The Council of State Governments.

The National Alliance for Caregiving and AARP. 2020. Caregiving in the u.S. 2020. The National Alliance for Caregiving and AARP.

Tomer, A., and J.W. Kane. 2020. How to protect essential workers during covid-19. In Brookings Report. Washington, DC: Brookings Institute.

U.S. Cybersecurity and Infrastructure Security Agency. 2020. Critical infrastructure sectors. Washington, DC: U.S. Cybersecurity and Infrastructure Security Agency.

World Health Organization. 2018. Managing epidemics: Key facts about major deadly diseases. Geneva, Switzerland: World Health Organization.

—. 2020. Coronavirus disease (covid-19) pandemic. Geneva, Switzerland: World Health Organization.

Yong, E. 2020. "How the pandemic defeated america." The Atlantic.

Ziebarth, N.R., and M. Karlsson. 2010. "A natural experiment on sick pay cuts, sickness absence, and labor costs." Journal of Public Economics 94 (11-12):1108-1122.

Ziebarth, N.R., and M. Karlsson. 2014. "The effects of expanding the generosity of the statutory sickness insurance system." Journal of Applied Econometrics 29 (2):208-230. 